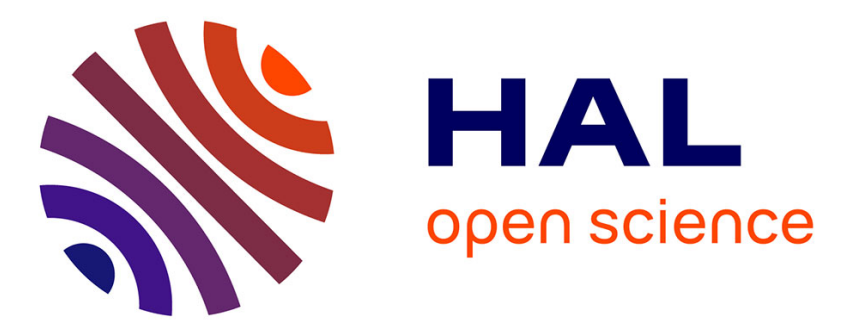

\title{
Batch cooling solution crystallization of ammonium oxalate in the presence of impurities: Study of solubility, supersaturation, and steady-state inhibition
}

Gilles Févotte, Nesrine Gherras, Jacques Moutte

\section{- To cite this version:}

Gilles Févotte, Nesrine Gherras, Jacques Moutte. Batch cooling solution crystallization of ammonium oxalate in the presence of impurities: Study of solubility, supersaturation, and steady-state inhibition. Crystal Growth \& Design, 2013, 13 (7), pp.2737-2748. 10.1021/cg301737s . hal-00913179

\author{
HAL Id: hal-00913179 \\ https://hal.science/hal-00913179
}

Submitted on 16 Dec 2013

HAL is a multi-disciplinary open access archive for the deposit and dissemination of scientific research documents, whether they are published or not. The documents may come from teaching and research institutions in France or abroad, or from public or private research centers.
L'archive ouverte pluridisciplinaire $\mathbf{H A L}$, est destinée au dépôt et à la diffusion de documents scientifiques de niveau recherche, publiés ou non, émanant des établissements d'enseignement et de recherche français ou étrangers, des laboratoires publics ou privés. 


\title{
Batch cooling solution crystallization of ammonium oxalate in the presence of impurities: study of solubility, supersaturation and steady-state inhibition.
}

\author{
Gilles FEVOTTE ${ }^{\mathrm{a}, \mathrm{b}}$, Nesrine GHERRAS ${ }^{\mathrm{c}}$, Jacques MOUTTE ${ }^{\mathrm{d}}$ \\ a Ecole des Mines de Saint Etienne, Centre SPIN, LGF, Département PROPICE, UMR CNRS \\ 5307, 158, cours Fauriel. 42023 Saint Etienne (France) \\ b Université de Lyon, Université Lyon 1, 43 blvd du 11 Novembre 1918. \\ 69100 Villeurbanne (France) \\ ${ }^{\mathrm{c}}$ Ecole des Mines de Saint Etienne, Centre SPIN, Département GENERIC, LPMG, UMR CNRS \\ 5148, 158, cours Fauriel. 42023 Saint Etienne (France) \\ d Ecole des Mines de Saint Etienne, Centre SPIN, Département GSE, EVS, UMR CNRS 5600, \\ 158, cours Fauriel. 42023 Saint Etienne (France
}

\begin{abstract}
.
When compared to equilibrium data in pure solvent, variations of solubility are frequently observed in the presence of dissolved impurities. It is also well-known that impurities can inhibit the crystallization processes and lead to supersaturation barriers below which the growth of crystals is cancelled. However, many papers dealing with the inhibiting effects of impurities in solution crystallization are rather unclear about the appropriate way of expressing the supersaturation in impure media. Indeed, as suggested in the present work, the latter can be defined either with respect to the solubility in pure solvent or in reference to the solubility of the impure solvent. Setting the correct reference for computing supersaturation in impure solutions is obviously a key-issue for understanding and modeling the dynamics of elementary crystallization phenomena (i.e. primary and secondary nucleation, crystal growth, etc.) The present case-study aims at clarifying this point. Solubility data were acquired thanks to in situ ATR FTIR measurements of the concentration of ammonium oxalate in pure water and in impure water containing various concentrations of nickel sulfate dissolved as impurity. Supersaturation thresholds were observed and analyzed, according to the theoretical framework of Kubota-Mullin impurity adsorption model. The experimental thresholds are confronted to the solubility drifts resulting from the
\end{abstract}


pollution of the pure solvent by impurities. It is finally proposed to consider the impuritydependent solubility as the appropriate reference for defining supersaturation. 


\section{Introduction.}

This paper reports partial results of a broader study devoted to the investigation of the effects of impurities during batch cooling crystallization processes. For this purpose, the crystallization of ammonium oxalate in water with nickel sulfate as impurity was selected as a model system. In a previous paper, the nucleation and growth kinetics of the pure solute/solvent system were first characterized ${ }^{1}$. Nickel sulfate was previously reported to inhibit the growth of ammonium oxalate (AO) crystals. Before analyzing and modeling the batch cooling crystallization of $\mathrm{AO}$ in the presence of $\mathrm{NiSO}_{4}$, it was essential to characterize the equilibrium features of the impure system, that is to say the solubility data and the way in which the final steady-state of the solid/liquid system is reached through crystallization. In fact, it is well known that the equilibrium solute concentration might differ from the solubility in the presence of impurities. Such possible difference between the steady-state concentrations of pure and impure systems is sometimes referred to as supersaturation threshold in the literature.

Considering that the "pure solubility" denoted as $C_{0}^{*}(T)$ in the following refers to the solubility of AO in pure water, low concentrations of dissolved impurities usually increase the actual solubility such that $C_{i m p}^{*}(T)>C_{0}^{*}(T)$. Surprisingly, such variations of solubility are rarely taken into account in studies dealing with process engineering and/or kinetics of crystallization in real media. This lack of interest for the effects of impurities is all the more surprising that, notably in the industrial context, the presence of impurities is quite inevitable while both increases of solubility and growth inhibition effects are often observed. The latter raise obvious concerns regarding the quality and the productivity of batch crystallizers.

Inhibition of crystal growth induced by the presence of impurities is widely reported in the literature, but this problem is usually investigated through the experimental study of single crystals performed in specific experimental devices ${ }^{2,3}$. Growth inhibition is of tremendous importance, particularly in the case of complex multicomponent systems. This is a critical issue, for example, in biological media ${ }^{4,5,6}$, geological systems ${ }^{7,8}$ etc., and in the case of industrial crystallization operations ${ }^{9}$ Indeed, due to the complexity of the many upstream chemical and separation unit operations, impurities are almost unavoidable in industrial 
processes, at least as secondary products of the many chemical reactions implemented upstream. Growth inhibitions can result in the cessation of the growth of crystals even when supersaturation is not fully consumed. The yield of solid is thus reduced. The effect of impurities is also undesirable because unwanted growth rate reductions require increasing the duration of the crystallization operation. When supersaturation thresholds are observed at the end of solution crystallization operations performed in the presence of impurities, it is therefore not clear whether they should be attributed to growth inhibition effects and/or to solubility drifts. As far as process understanding and modeling is concerned, this is clearly an important issue. Through experimental and theoretical investigations, this work is intended to shed some light on the notion of supersaturation threshold.

In the presence of solubility variations it seems rather logical to compute supersaturation with respect to the actual solubility in impure solvent. Neglecting the presence of impurities in crystallizing media might lead to overestimate (or underestimate) supersaturation and, consequently, to underestimate (or overestimate) the effective basic crystallization rates. Despite its obvious importance in crystallization kinetics and process dynamics studies, this particular question is almost never addressed in papers dealing with the evaluation of crystallization kinetic effects induced by impurities. Considering the problem of the definition of appropriate reference solubility in impure inhibiting media, two different standpoints can actually be adopted to interpret the observation of steady-state supersaturation thresholds. The first approach assumes that supersaturation thresholds actually result from erroneous interpretation of solubility increases. The second approach consists in confronting experimental and theoretical aspects of the notion of supersaturation thresholds on the ground of crystal growth inhibition models (e.g. Kubota-Mullin pinning model.) Both viewpoints are examined in the following.

The paper is organized as follows. After presenting the experimental means implemented during the work, Part 3 is focused on solubility measurements obtained in pure water (Part 3.1) and in the presence of varying concentrations of dissolved nickel sulfate (Part 3.2.) For interpreting these experimental results, a speciation study of the impure system is presented in Part 3.3. In order to get an additional point of view on the solubility study, Part 3 is completed by a brief analysis of the variations of the dissolution enthalpy with varying concentrations of impurities. Part 4 is then devoted to the evaluation of possible steady- 
state supersaturation thresholds in impure water. Experimental results are presented and analyzed in Part 4.1 and compared with molecular modeling estimates of the adsorption of the involved impurity species on the two main AO crystal faces in Part 4.2. Thanks to the adsorption energies computed using molecular simulation, Part 5 finally presents a basic quantitative approach of supersaturation thresholds.

\section{Experimental crystallization setup and continuous in situ measurements of} supersaturation during the crystallization of ammonium oxalate monohydrate.

Cooling ammonium oxalate $(\mathrm{AO})$ crystallization operations were performed in pure water and in water containing dissolved $\mathrm{NiSO}_{4}$ impurities. The choice of dissolved nickel sulfate was essentially motivated by the availability of the many published data concerning the effect of $\mathrm{Ni}^{2+}$ ions on the growth rate of $\mathrm{AO}$ in water ${ }^{10,11}$. Supersaturation measurements were performed using in situ ATR FTIR spectroscopy. The operating mode and the calibration procedure required by the spectroscopic technique were presented elsewhere ${ }^{1}$, and will not be recalled here. The lab-scale instrumented crystallizer used for the experiments is presented in Fig.1. More details about the experimental setup are given in the preceding reference.

AO solubility measurements were done in pure water and in water containing dissolved nickel sulfate, as presented below. Batch cooling unseeded crystallization experiments were then carried out with constant cooling rates. The kinetics of crystallization of AO in pure water was identified and the modeling results were published ${ }^{12}$. Two different crystallization regimes were highlighted and the corresponding nucleation and growth kinetics were characterized, according to the rate of cooling (i.e. the rate of generating supersaturation). To investigate the variations of solubility in impure water, the following set of impurity concentrations was explored: $C_{\text {imp }}=\left[6\right.$ 10-3; 2 10-2; 4 10-2] mol. $\mathrm{L}^{-1}$. 


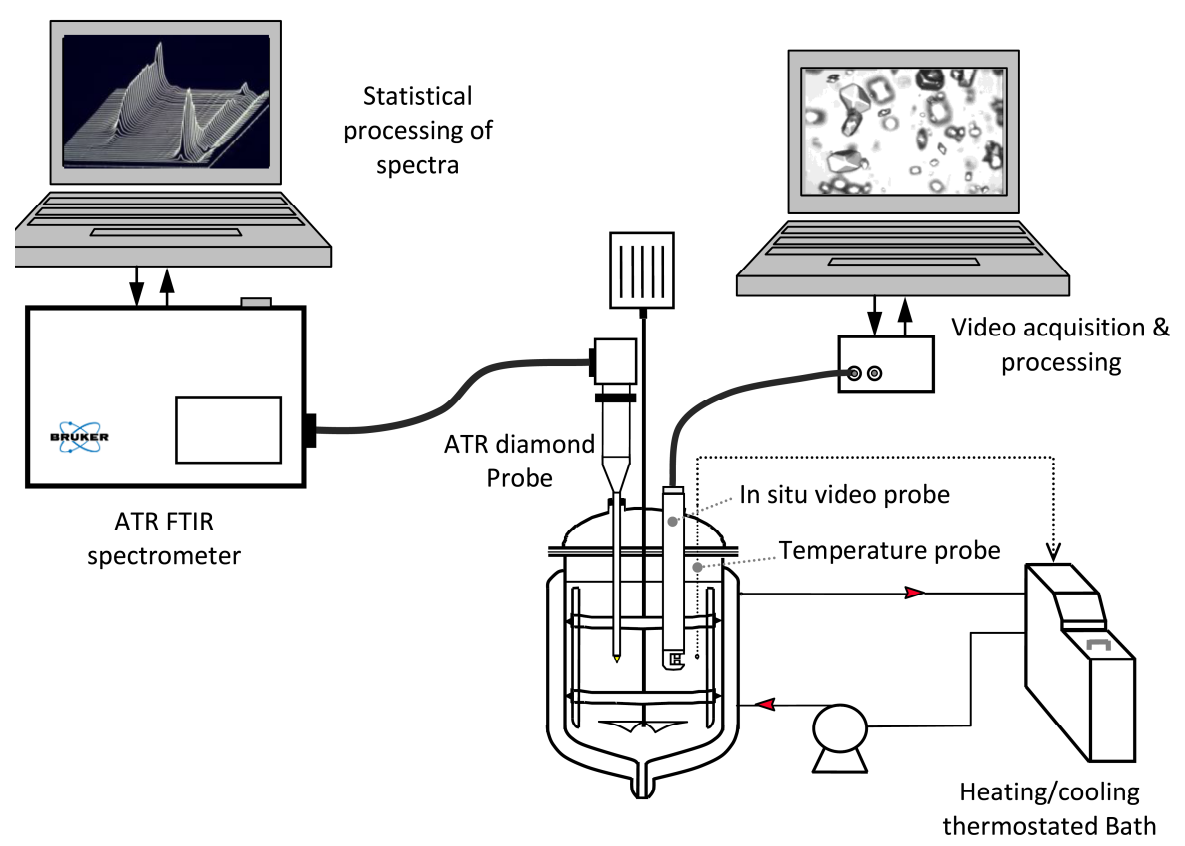

Figure 1: Experimental set up: temperature controlled well-mixed batch crystallizer equipped with in situ ATR-FTIR diamond probe and in situ image acquisition device.

\section{Solubility of ammonium oxalate in pure water and the presence of low $\mathrm{NiSO}_{4}$ concentrations.}

\subsection{Solubility in pure water, experimental results.}

Two different operating procedures were used to measure the solubility of $A O$ in pure water and in the presence of dissolved nickel sulfate; both experimental strategies taking advantage of the availability of "continuous" in situ ATR FTIR concentration measurements through the application of successive isothermal/poly-thermal dissolution and crystallization steps $^{13}$. As shown in Fig.2, a first method consists in cooling AO from a temperature of about $62^{\circ} \mathrm{C}$. After reaching the metastable zone, the onset of primary nucleation, at a temperature of about $50^{\circ} \mathrm{C}$, can be observed in Fig.2. The decreasing solute concentration was then quantitatively monitored using ATR spectroscopy. For rapidly growing crystals, provided that the cooling rate is sufficiently low, it can be assumed that the concentration trajectory matches the solubility (i.e., supersaturation is negligible). The measured concentration trajectory thus provides a continuous estimate of the solubility. The same approach can also be reproduced through heating, assuming that the level of undersaturation is also negligible during the dissolution process. In the case of pure water, the fact of applying both heating 
and cooling procedures ensures that the solubility equilibrium is truly reached. Indeed, should the crystallization and/or dissolution dynamics be underestimated the cooling concentration trajectory will be located above the heating trajectory. The coincidence of both curves therefore confirms that the estimation of the solubility curve is correct. This overall continuous solubility measurement method is referred below to as Dynamic Heating/Cooling Solubility Approach (DHCSA)

Figure 2 shows the results obtained after applying the DHCSA: the 2 curves measured through ATR FTIR spectroscopy are almost identical to data published by ${ }^{14}$. The relative uncertainty between the measured solubility data is only of the order of $0.12 \%$. It should however be noted that data previously reported ${ }^{15}$ are unexpectedly about $5.5 \%$ lower than our experimental results. The following polynomial expression was finally fit to the spectroscopic measurements:

$$
C_{0}^{*}(T)=2.2710^{-5}\left( \pm 6.710^{-8}\right) T^{2}+5.3910^{-4}\left( \pm 5.610^{-6}\right) T+2.8710^{-2}\left( \pm 4.810^{-3}\right)
$$

where $C_{0}^{*}(T)$ is the solubility concentration in pure water in $\mathrm{kg} \mathrm{AO} / \mathrm{kg}$ solution and $T$ is the temperature in ${ }^{\circ} \mathrm{C}$.

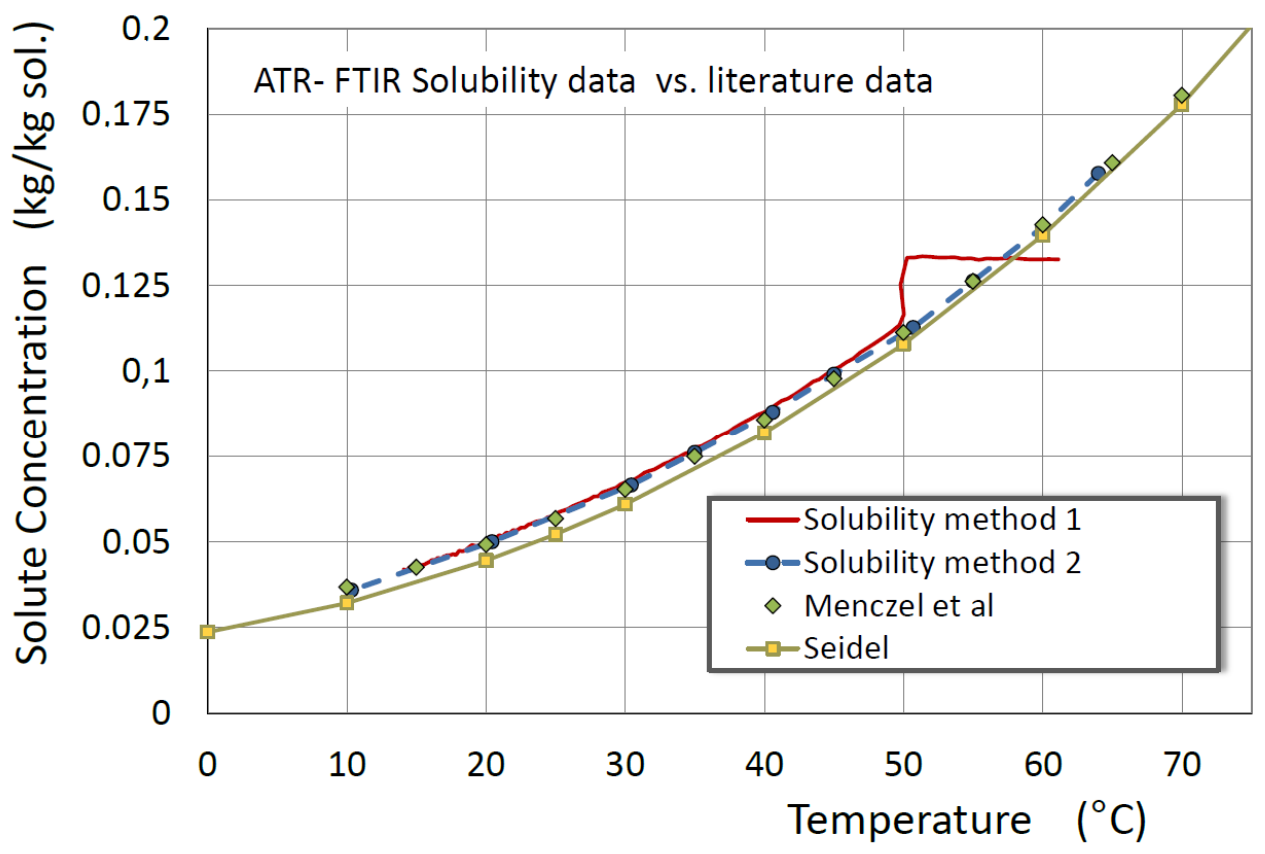

Figure 2: Continuous measurements (DHCSA) of the solubility of AO in pure water, using a slow cooling crystallization procedure (Method 1) followed by a slow heating dissolution process (Method 2), and comparison with two literature data sets. The average relative uncertainty between cooling (method 1 ) and heating (method 2) and data after Menczel et al. $^{14}$ is about $0.12 \%$. 
Figure 2 shows that both heating and cooling plots differ only imperceptibly, and therefore allow computing an accurate average solubility curve. A second approach for the determination of solubility consists in implementing successive positive or negative temperature increments. At every steady-state temperature stage, the time variations of Mid-IR spectra are monitored until a constant spectrum can be recorded. Using calibration models, the recorded spectra allows computing the equilibrium solute concentration. This second approach is referred below to as Static Heating/Cooling Solubility Approach (SHCSA). As in the case of DHSCA, it is clear that both steady state crystallization and dissolution measurements are necessary to confirm the achievement of the "true thermodynamic equilibrium".

\subsection{Solubility with dissolved $\mathrm{NiSO}_{4}$, experimental results}

Both SHCSA and DHSCA were applied to the evaluation of the solubility of ammonium oxalate in the presence of varying concentrations of $\mathrm{NiSO}_{4}$. A saturated $\mathrm{AO}$ solution was prepared at $60^{\circ} \mathrm{C}$ and slowly cooled with a rate of $2^{\circ} \mathrm{C} / \mathrm{h}$ until a final temperature of $10^{\circ} \mathrm{C}$. Successive temperature steps were then performed from $10^{\circ} \mathrm{C}$ to $60^{\circ} \mathrm{C}$. During each step the temperature was kept constant during a $30 \mathrm{~h}$ period. 240 ATR spectra were recorded after $30 \mathrm{~h}$ stabilization with a sampling period of 30 s (i.e. for a period of 2 hours.) As displayed in Fig 3, three different dissolved impurity concentrations were selected: $C_{i m p}=[0.04 ; 0.02$; 0.006] $\mathrm{mol} \mathrm{NiSO}_{4} \cdot \mathrm{L}^{-1}$. Solubility data obtained at $30^{\circ} \mathrm{C}$, published by Sangwal and MielniczekBrzoska $^{11}$, is also presented in Fig. 3 in insert, the reported results are in good agreement with our experimental results.

In the presence of different impurity concentrations, the parameters of the following polynomial expression were estimated, where $C_{i m p}^{*}(T)$ is the solubility in $\mathrm{kg}$ AO monohydrate/kg de solution:

$$
C_{i m p}^{*}\left(T, C_{i m p}\right)=a T^{2}+\mathrm{b} \mathrm{T}+\mathrm{c}
$$

The estimated parameters a,b,c are displayed in Table 1. 
Figure 3 shows that below a temperature located around $50-55^{\circ} \mathrm{C}$, the difference between the $\mathrm{AO}$ solubilities, with and without $\mathrm{NiSO}_{4}$ impurities, increases for increasing impurity concentrations and decreasing temperatures. It also appears that, within the limits of the arbitrary fit of the second order polynomial eq.(2), the solubility of AO with $610^{-3} \mathrm{~mol} . \mathrm{L}^{-1}$ dissolved $\mathrm{NiSO}_{4}$ matches the solubility of the pure system. Above $55^{\circ} \mathrm{C}$, as presented in more details in the sequel, the solubility drift observed with the two "high" impurity concentrations is difficult to estimate and, as a first approximation, can be considered negligible (i.e. within the limits of the concentration measurements)

In a study dedicated to the effect of cationic impurities on the solubility of $A O$, the following empirical relationship was proposed ${ }^{11}$ where $A_{S}$ is a constant depending the cationic impurity specie:

$$
C_{i m p}^{*}=C_{0}^{*}+A_{S} C_{i m p}
$$

Unfortunately, Eq. (3) was evaluated only at $30^{\circ} \mathrm{C}$. For $\mathrm{Ni}^{2+}$, the parameter value $A_{S}=1.676$ \pm 0.06 was proposed by the authors with $C_{0}^{*}=0.496 \mathrm{~mol} / \mathrm{L}$ (the solubility of $A O$ in pure water.) Considering the results presented above, Eq.(3) predicts an increase in solubility proportional to the concentration of impurity, which is not observed in Fig.3. Denoting $\Delta C_{i m p}^{*}=C_{i m p}^{*}-C_{0}^{*}$, the difference between the solubility in impure solvent and the solubility in pure water $C_{0}^{*}$, Fig. 4 presents experimental results expressed as a function of temperature and impurity concentration. These results were computed using Eq. (2) and the estimated parameters are given in Table 1. 


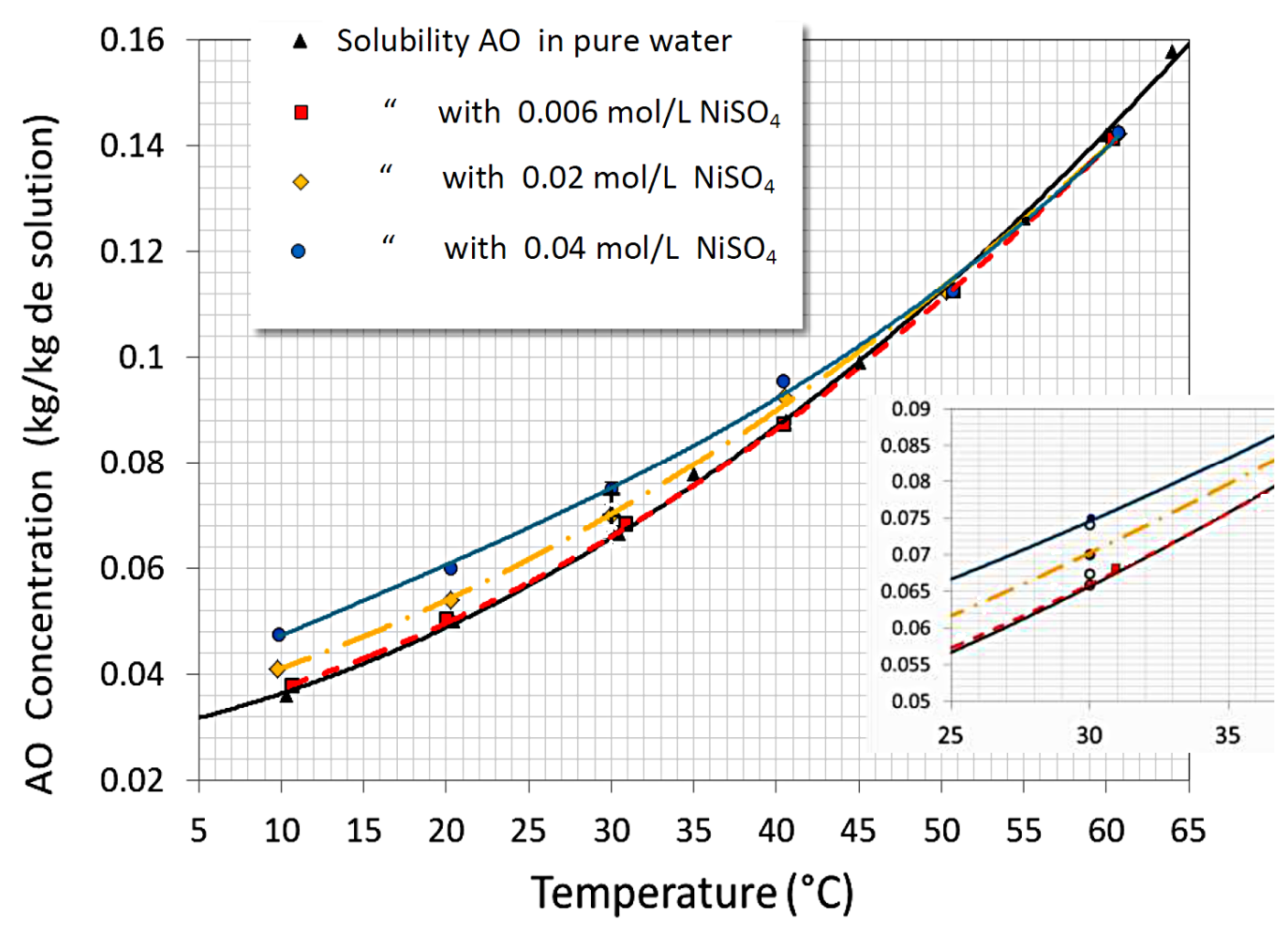

Figure 3. Measured solubility curves of $A O$ (in $\mathrm{kg} \mathrm{AO} / \mathrm{kg}$ solvent) in pure solvent and with varying concentrations of $\mathrm{NiSO}_{4}$. Insert: data from ${ }^{11}$. "smoothed" Cooling DHSCA data (Continuous line) and heating SHSCA data (full points)

Table 1. Parameter estimates for the polynomial approximation of the solubility curves of ammonium oxalate with different concentrations of dissolved nickel sulfate (see eq.2)

\begin{tabular}{|c|c|c|c|c|}
\hline $\mathrm{C}_{\mathrm{i}}(\mathrm{mol} / \mathrm{L})$ & $\mathrm{a}$ & $\mathrm{b}$ & $\mathrm{c}$ & $\mathrm{R}^{2}$ \\
\hline 0 & $2.2710^{-5}$ & $5.3910^{-4}$ & $2.8710^{-2}$ & 0.999 \\
\hline 0.0006 & $2.0610^{-5}$ & $6.0610^{-4}$ & $2.9210^{-2}$ & 0.999 \\
\hline 0.02 & $1.7210^{-5}$ & $7.6810^{-4}$ & $3.1710^{-2}$ & 0.999 \\
\hline 0.04 & $1.6410^{-5}$ & $6.7310^{-4}$ & $4.010^{-2}$ & 0.999 \\
\hline
\end{tabular}




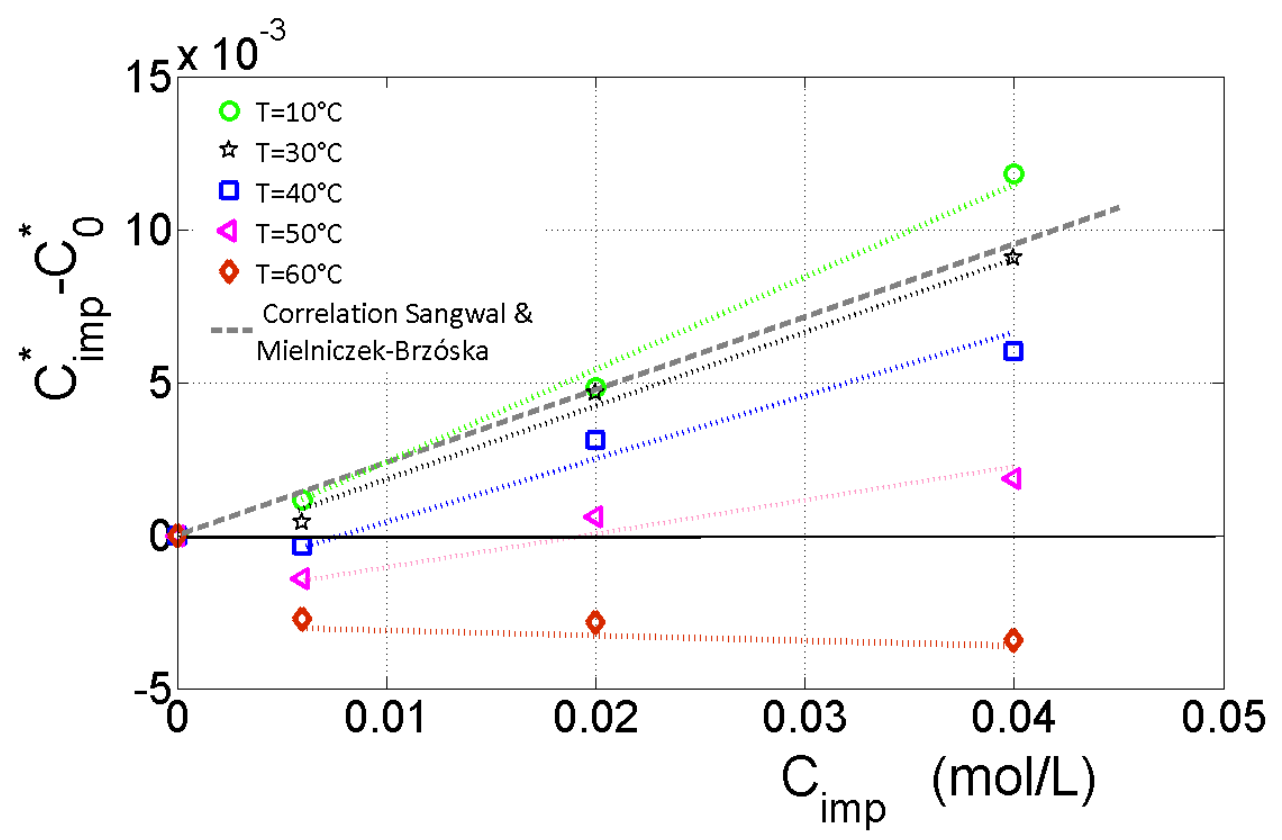

Figure 4. AO solubility variations $\Delta \mathrm{C}^{*}{ }_{\mathrm{imp}}$ computed using the experimental results displayed in Fig. 3 with temperature varying between 10 and $60^{\circ} \mathrm{C}$.

As published by Sangwal and Mielniczek-Brzoska ${ }^{11}$, the solubility increases proportionally to the impurity concentrations at low temperatures. Fig.4 shows that the slope of the variations agrees quite well with the value of $A_{s}$ (see Eq.(3)) proposed by Sangwal and MielniczekBrzoska ${ }^{11}$. However, above $50^{\circ} \mathrm{C}$, the $A_{s}$ seems to decrease and tends to zero for increasing temperatures. Moreover, due to the measurements uncertainties, the general trend of the solubility drift at low impurity concentration remains unclear. Anyway, the results suggest that above $50^{\circ} \mathrm{C}$ the solubility in the presence of impurities might be lower than the solubility in pure water.

The variations of solubility with the concentration of impurities can have several explanations. First, the composition of the solution could vary due to the formation of new chemical species resulting from solute/solvent/impurity interactions (e.g. formation of new complexes, chemical reactions, formation of new solvates, etc.) Second, the impurity could incorporate into the crystal lattice which, consequently, could behave as a new solid phase. Also, in the presence of impurities, both solid and liquid phase variations might also take place in the neighborhood of the growing crystal surface. This is the reason why, to evaluate the possible incorporation of impurities in the crystal, analyses of the solid were performed. Final suspension samples were withdrawn from the reactor, filtered and washed quickly with 
cold water in order to remove residual mother liquor. For an impurity concentration of 0.02 mol. ${ }^{-1} \mathrm{NiSO}_{4}, \mathrm{X}$-ray diffraction did not allow concluding to any alteration of the AO crystal structure. XPS showed traces of nickel and almost undetectable traces of sulfur at the crystal surface, while Raman spectroscopy revealed very slight differences that could be related to small changes of the crystal lattice (i.e., appearance of tiny bands and slight shifts). The characterization of the solids therefore suggests that small amounts of $\mathrm{Ni}$ and sulfate species are present at the crystal surface, without being incorporated into the crystal lattice.

\subsection{Speciation of the $\mathrm{AO} / \mathrm{NiSO}_{4} / \mathrm{H}_{2} \mathrm{O}$ system}

According to the previous observations, one can attribute the variations of solubility to the effect of the dissolution of $\mathrm{NiSO}_{4}$ on the speciation of the $\mathrm{AO}$ solution and, perhaps, to the alteration of the solid surface by adsorbed impurities. Actually, as far as the chemistry of ionic impure solutions is concerned, ammonium oxalate dissociates in several species which are likely to change with temperature and through interactions with dissolved impurities. A theoretical study of the speciation of the solution was thus performed, firstly to evaluate the impact of dissolved nickel sulfate on the chemical composition of the crystallizing suspensions at the solubility equilibrium, secondly to check the effect of temperature on the speciation of the solution.

The dissociation of $A O$ in pure water involves the following chemical equilibria ${ }^{11}$ :

$\begin{array}{llll}{\left[\left(\mathrm{NH}_{4}\right)_{2} \mathrm{C}_{2} \mathrm{O}_{4}, \mathrm{H}_{2} \mathrm{O}\right] \text { solid }} & \rightarrow & {\left[\left(\mathrm{NH}_{4}\right) \mathrm{C}_{2} \mathrm{O}_{4}\right]^{-} \text {Soluble complex }+\mathrm{NH}_{4}{ }^{+}} & -\log \mathrm{k}_{1}\left(25^{\circ} \mathrm{C}\right)=0.92 \\ {\left[\left(\mathrm{NH}_{4}\right) \mathrm{C}_{2} \mathrm{O}_{4}\right]^{-}} & \rightarrow & \mathrm{NH}^{4+}+\mathrm{C}_{2} \mathrm{O}_{4}{ }^{-2} & -\log \mathrm{k}_{2}\left(25^{\circ} \mathrm{C}\right)=1.43 \\ \mathrm{C}_{2} \mathrm{O}_{4}{ }^{-2}+\mathrm{H}_{2} \mathrm{O} & \rightarrow & \left.-\log \mathrm{HC}_{2} \mathrm{O}_{4}{ }^{-}+\mathrm{OH}^{-} \mathrm{C}\right)=10.2 \\ \mathrm{HC}_{2} \mathrm{O}_{4}^{-}+\mathrm{H}_{2} \mathrm{O} & \rightarrow & -\log \mathrm{H}_{4}\left(25^{\circ} \mathrm{C}\right)=8.8 \\ \mathrm{NH}_{4}{ }^{+}+\mathrm{H}_{2} \mathrm{O} & \rightarrow \mathrm{OH}^{-} & -\log \mathrm{k}_{5}\left(25^{\circ} \mathrm{C}\right)=4.75\end{array}$




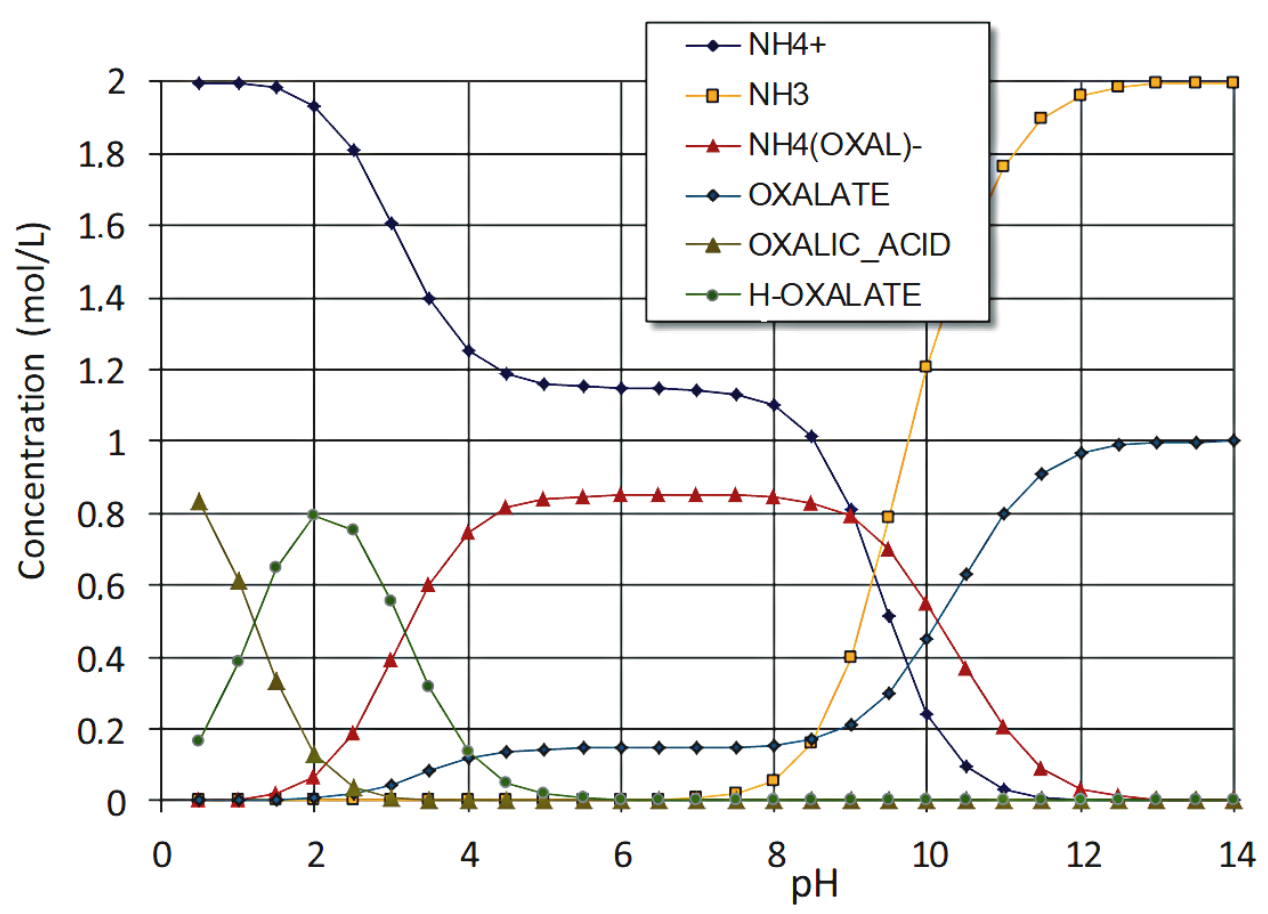

Figure 5. Variations with $\mathrm{pH}$ of the concentrations of the various solute species for a 1 molal AO solution at $\mathrm{T}=25^{\circ} \mathrm{C}$.

The speciation model was computed using ARXIM, a program developed at the School of Mines of Saint Etienne. The aqueous species taken in consideration in the $\mathrm{H}_{2} \mathrm{O}-\mathrm{AO}-\mathrm{NiSO}_{4}$ system are those available in the latest update (slop07.dat) of the SUPCRT database for calculation of temperature dependent properties of aqueous species according to the Helgeson-Kirkham-Flowers (HKF) equation of state ${ }^{16}$. Concerning oxalate-bearing species, this database integrates the datasets from refs ${ }^{17,18}$. Table 2 gives the equilibrium constants computed with ARXIM at different temperatures according to the HKF equations. The values are given for the reactions of formation from the following primary species: $\mathrm{H}_{2} \mathrm{O}, \mathrm{H}^{+}, \mathrm{C}_{2} \mathrm{O}_{4}{ }^{-2}$, $\mathrm{NH}_{4}{ }^{+}, \mathrm{Ni}^{+2}, \mathrm{SO}_{4}{ }^{-2}$. Besides aqueous species, the equilibrium constants for the dissolution of ammonium oxalate salt, not found in the database, were calculated as a function of temperature, using the experimental solubility data.

Considering the high ionic strength of AO-saturated solutions, activity coefficients should be computed using specific interaction models (e.g. Pitzer or SIT approach), but, as such interaction coefficients are currently not available for all species in consideration, activity coefficients have been computed according to a more general truncated Davies model ${ }^{19}$, which gives at least a semi-quantitative understanding of the role of oxalate complexes. The equation proposed for the activity coefficient of the charged solute species $i$ is as follows: 


$$
\ln \gamma_{\mathrm{i}}=\mathrm{A} \mathrm{z}_{\mathrm{i}}^{2}\left(\frac{\sqrt{\mathrm{I}}}{1+3.72 \mathrm{~B} \sqrt{\mathrm{I}}}+\left(0.2-4.17 \times 10^{-5} \mathrm{I}\right) \times \mathrm{I}\right)
$$

where $A$ and $B$ are temperature dependent solvent parameters, $I$ is ionic strength of solution, and $z_{i}$ is the charge of the solute species considered. This adaptation is considered to expand the validity of the Davies equation to ionic strength up to $1.5 \mathrm{~mol} . \mathrm{L}^{-1}$.

Figure 5 shows the computed repartition of dissolved species, in the case of the pure AOwater system, as a function of $\mathrm{pH}$. As batch cooling experiments are performed between 50 and $10^{\circ} \mathrm{C}, \mathrm{pH}$ evolves between 6 and 7.2 , one can see that 3 species are predicted to coexist during the whole crystallization process at almost constant concentration: ammonium and oxalate ions and the complex anion $\left[\left(\mathrm{NH}_{4}\right) \mathrm{C}_{2} \mathrm{O}_{4}\right]^{-}$; the latter being involved in the crystallization process.

As for the pure system, a study of speciation accounting for the effect of dissolved nickel sulfate was again performed using $\mathrm{ARXIM}^{\circledR}$. The equilibrium constants which are not available in the literature were calculated as a function of temperature, using the experimental solubility data. The computation was performed with saturated oxalate solutions at temperatures varying between $25^{\circ} \mathrm{C}$ and $50^{\circ} \mathrm{C}$ and $\mathrm{NiSO} 4$ concentrations between 10-12 and $0.095 \mathrm{~mol}^{-1}$. The speciation model shows that increasing the concentration of dissolved $\mathrm{NiSO}_{4}$ decreases the concentrations of oxalate, $\mathrm{H}$-oxalate and $\mathrm{NH} 4-$ oxalate ions while the concentration of $\mathrm{NH}^{4+}$ ions increases. For example, with a concentration of $\mathrm{NiSO}_{4}$ of $0.095 \mathrm{~mol} . \mathrm{L}^{-1}, \mathrm{pH}=6.16$ at $25^{\circ} \mathrm{C}$ and 5.84 at $50^{\circ} \mathrm{C}$. Nickel in solution is present as aquo-complexes involved in acid-base reactions that release $\mathrm{H}_{3} \mathrm{O}^{+}$ions. Consequently, the $\mathrm{pH}$ decreases and thus affects the speciation of oxalates and ammonium ions. Moreover, oxalate ions are trapped in soluble nickel complexes, their concentration is approximately equivalent to the concentration of dissolved nickel sulfate. The concentration of ammonium ions increases in the same proportions. 
Table 2. Equilibrium constants of the aqueous species computed according to the HKF equation of state. The values are for the reactions of formation from the following set of primary species: $\mathrm{H}_{2} \mathrm{O}, \mathrm{H}^{+}, \mathrm{C}_{2} \mathrm{O}_{4}{ }^{-2}, \mathrm{NH}_{4}{ }^{+}, \mathrm{Ni}^{+2}, \mathrm{SO}_{4}{ }^{-2}$. The constants for ammonium oxalate salt were calculated from the solubility data, using the same activity model as used in subsequent equilibrium calculations

\begin{tabular}{|l|cccccc|}
\hline $\mathrm{T}\left({ }^{\circ} \mathrm{C}\right)$ & 10 & 20 & 25 & 30 & 40 & 50 \\
\hline $\mathrm{OH}^{-}$ & -14.52 & -14.16 & -13.99 & -13.83 & -13.53 & -13.26 \\
\hline $\mathrm{HSO}_{4}^{-}$ & 1.81 & 1.92 & 1.98 & 2.04 & 2.17 & 2.3 \\
\hline $\mathrm{NH}_{3}$ & -9.72 & -9.4 & -9.24 & -9.09 & -8.81 & -8.54 \\
\hline $\mathrm{NiOH}^{+}$ & -11.31 & -10.96 & -10.8 & -10.63 & -10.31 & -10.01 \\
\hline $\mathrm{NiO}^{-}$ & -22.25 & -21.2 & -20.7 & -20.22 & -19.3 & -18.43 \\
\hline $\mathrm{HNiO}^{-2}$ & -32.17 & -31.37 & -30.99 & -30.62 & -29.9 & -29.23 \\
\hline $\mathrm{NiO}_{2}^{-2}$ & -45.88 & -44.62 & -44.02 & -43.45 & -42.36 & -41.35 \\
\hline $\mathrm{H}_{2} \mathrm{C}_{2} \mathrm{O}_{4}$ & 5.47 & 5.5 & 5.53 & 5.56 & 5.63 & 5.72 \\
\hline $\mathrm{HC}_{2} \mathrm{O}_{4}^{-}$ & 4.21 & 4.24 & 4.26 & 4.28 & 4.33 & 4.39 \\
\hline $\mathrm{Ni}^{-}\left(\mathrm{C}_{2} \mathrm{O}_{4}\right)$ & 5.16 & 5.16 & 5.16 & 5.17 & 5.21 & 5.25 \\
\hline $\mathrm{NH}_{4}\left(\mathrm{C}_{2} \mathrm{O}_{4}\right)^{-}$ & 0.9 & 0.91 & 0.92 & 0.94 & 0.98 & 1.03 \\
\hline$\left(\mathrm{NH}_{4}\right)_{2}\left(\mathrm{C}_{2} \mathrm{O}_{4}\right), \mathrm{s}$ & 2.57 & 2.24 & 2.09 & 1.95 & 1.71 & 1.47 \\
\hline
\end{tabular}

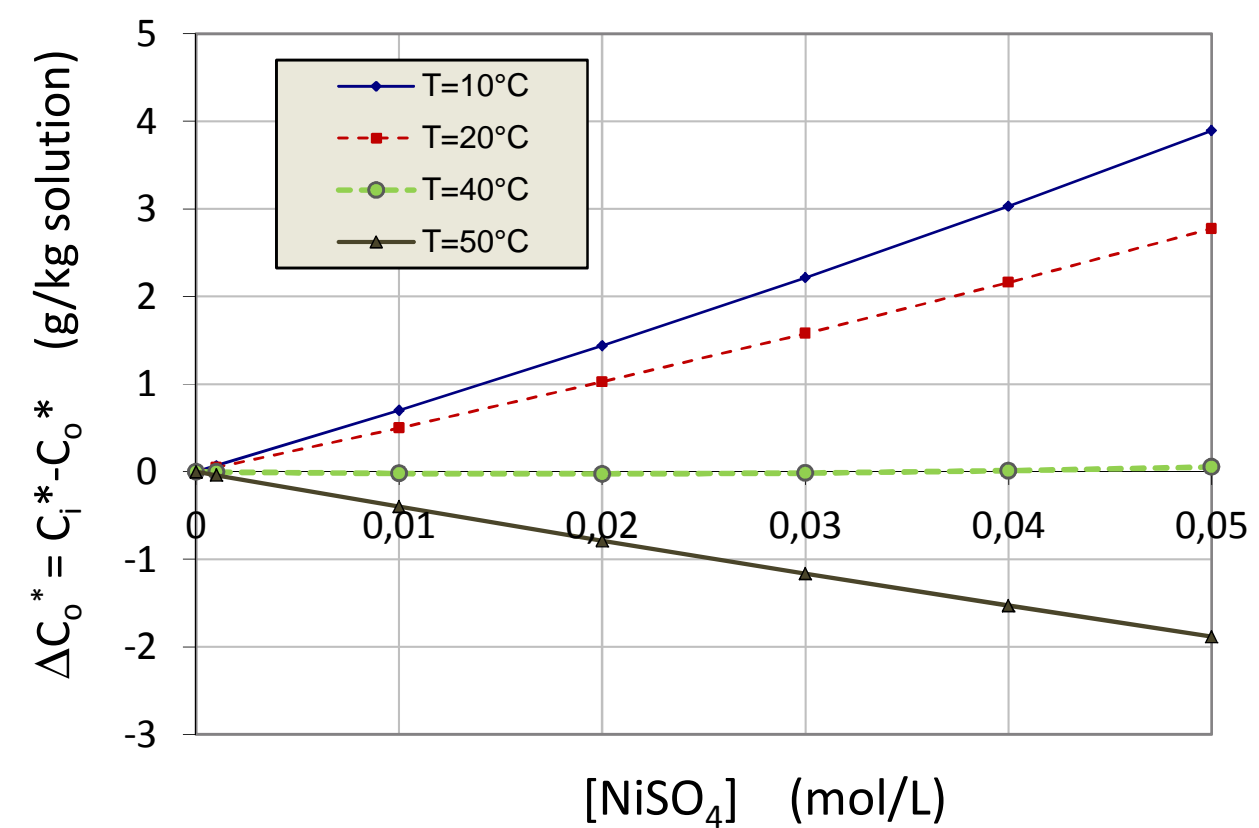

Figure 6. AO solubility variations $\Delta \mathrm{C}^{*}{ }_{\mathrm{imp}}$ computed using the model of speciation of the system $\left(\mathrm{AO}, \mathrm{NiSO}_{4}, \mathrm{H}_{2} \mathrm{O}\right)$ with increasing nickel sulfate concentrations and with temperature varying between 10 and $50^{\circ} \mathrm{C}$. 
The variations of the concentration of species in solution were computed as a function of the concentration of $\mathrm{NiSO}_{4}$ and of temperature. The results allowed evaluating the differences of solubility displayed in Fig.6. The amplitude of the experimental solubility variations is a little bit more than twice as high as the model predictions, but the main trends of the temperature dependence are consistently reproduced by the speciation model. Fig.6 also shows that according to the same model, the trend of the variations of solubility with the concentration of $\mathrm{NiSO}_{4}$ reverses around $40^{\circ} \mathrm{C}$. The same feature was also observed with the experimental results displayed in Fig. 4 around $50^{\circ} \mathrm{C}$.

Actually, the program ARXIM, used for speciation calculations, implements the HelgesonKirkham-Flowers (HKF) equation of state for aqueous species. The computations thus rely on the availability of HKF parameters that allows the computation of a set of dissociation constants for all species of interest. The latest update of the HKF-oriented database (slop07.dat) includes all the aqueous species that should be taken in consideration for speciation calculations in the $\mathrm{H}_{2} \mathrm{O}-\mathrm{AO}-\mathrm{NiSO}_{4}$ system, but it lacks data for the ammonium oxalate salt. We have thus derived the equilibrium constant of ammonium oxalate hydrate, at various temperatures, from experimental data on its solubility in the $\mathrm{H}_{2} \mathrm{O}-\mathrm{AO}$ system, using the speciation program ARXIM with the Davies - Samson activity model, and the data on all aqueous species of interest $\left(\mathrm{H}^{+}, \mathrm{OH}^{-}, \mathrm{SO}_{4}^{-2}, \mathrm{HSO}_{4}^{-}, \mathrm{NH}_{4}^{+}, \mathrm{NH}_{3}, \mathrm{C}_{2} \mathrm{O}_{4}^{-2}, \mathrm{H}_{2} \mathrm{C}_{2} \mathrm{O}_{4}, \mathrm{HC}_{2} \mathrm{O}^{4-}\right.$, $\left.\mathrm{NH}_{4}\left(\mathrm{C}_{2} \mathrm{O}_{4}\right)^{-}\right)$). It was then possible, using the same speciation program with the same activity model, and adding the Ni-related species $\left(\mathrm{Ni}^{+2}, \mathrm{NiOH}^{+}, \mathrm{NiO}, \mathrm{HNiO}^{-2}, \mathrm{NiO}_{2}^{-2}, \mathrm{Ni}\left(\mathrm{C}_{2} \mathrm{O}_{4}\right)\right)$, to compute the solubility of the ammonium oxalate salt for systems containing various amounts of $\mathrm{NiSO}_{4}$ and for different temperatures.

\subsection{Estimation of the dissolution enthalpy from solubility data}

The following Eq. (5) describes the temperature-dependence of the solubility in ideal solutions (i.e., the interactions between solute and solvent molecules is assumed to be equal to interactions the solute and the solvent molecules themselves ${ }^{20}$ ):

$$
\ln C^{*}(T)=\frac{\Delta H_{f}}{R T_{f}}\left(1-\frac{T_{f}}{T}\right)
$$


where $T_{f}$ is the solute fusion temperature and $\Delta H_{f}$ is the enthalpy of fusion.

For non-ideal solutions, it was proposed to approximate Eq. (5) as a function of the solution enthalpy $\Delta H_{\text {sol }}$. For exemple, ${ }^{14}$ expressed the solubility of salt hydrates as follows:

$$
\ln C^{*}(T)=\frac{\Delta H_{S o l}}{v R T_{m}}\left(1-\frac{T_{m}}{T}\right)
$$

The enthalpy of solution is expected to depend on the ratio between the solid and the solvent. This is why the heat of solution at infinite dilution, $\Delta H_{\text {sol }}^{\infty}$, is defined as the heat exchanged when one mole of solute is dissolved in an infinite volume of solvent. Parameter $v$ is expected ${ }^{14}$ to account for the incomplete dissolution of ammonium oxalate into oxalate and ammonium ions, and also for possible slight variations of the solubility product. For concentrated solutions, $v$ is usually set between 1 and $2 . v=1.5$ was assumed in the sequel. The plot of the experimental results $\ln \left(C^{*}\right)$ vs. $1 / T$ is displayed in Fig.7. The plot fits satisfactorily the model Eq. (6) and leads to the estimates of $\Delta H_{s o l}$ presented in Table 3. The average value for $\Delta H_{\text {sol }}$ in pure water is thus found to be very close to values reported by ${ }^{14}$ : $33.0 \pm 4.9 \mathrm{~kJ} / \mathrm{mol}$.

Table 3 shows that the solution enthalpy decreases for increasing impurity concentrations. As explained in the sequel, DSC analyses which were tried to evaluate the fusion enthalpy turned out to be unreliable. To the best of our knowledge, no thermodynamic data is available that would allow predictive model-based computation of the solubility from the knowledge of the concentration of impurity. Anyway the main trends of our experimental observations are rather well explained by the first approach of solution thermodynamics developed above. In particular, the fact that increasing impurity concentrations increase the solubility - the latter effect being amplified for decreasing temperature - is quite consistent with adsorption theories developed in the context of crystal growth ${ }^{2,21}$. 


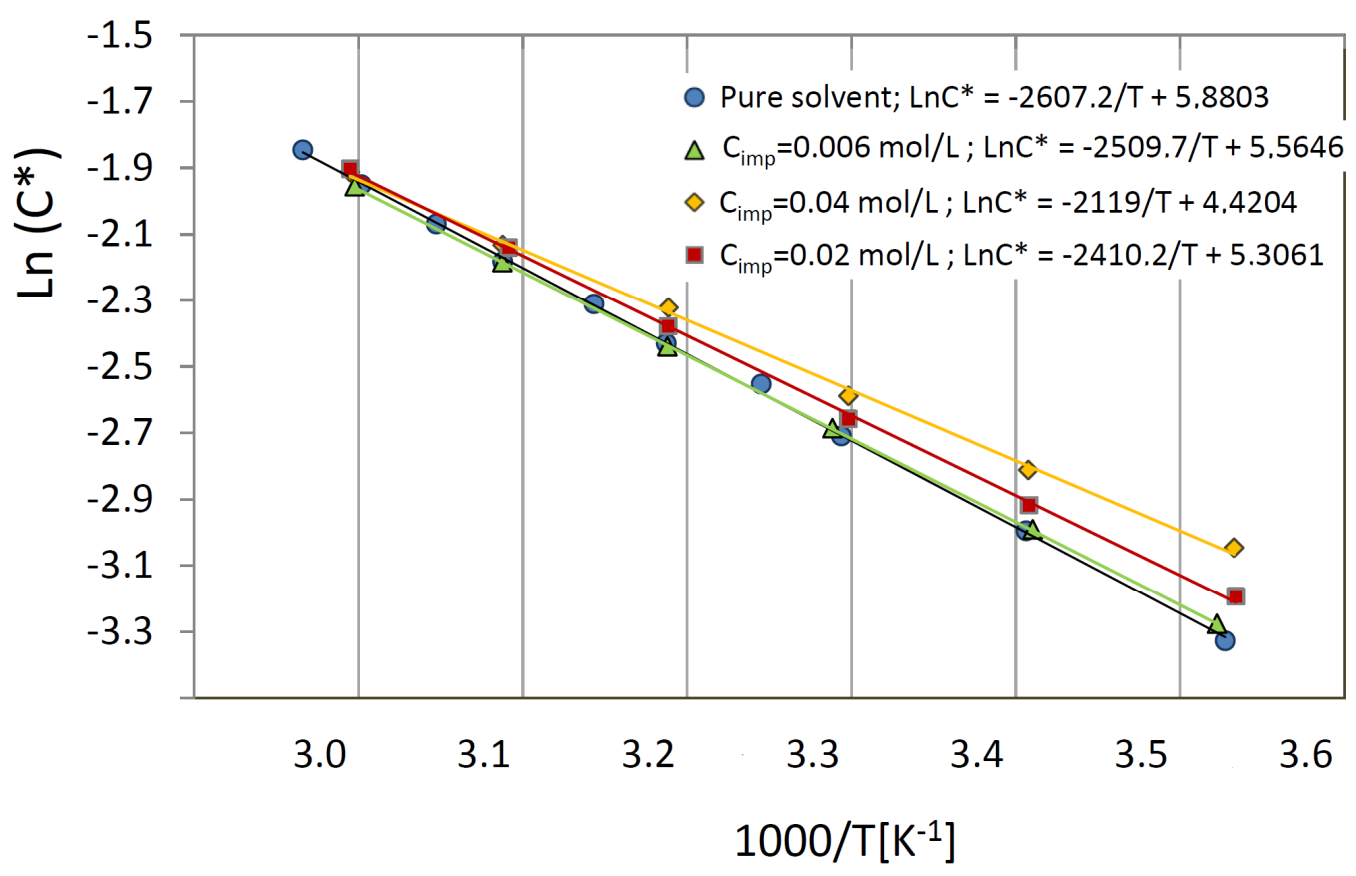

Figure 7. Plot of the logarithm of the solubility of ammonium oxalate (molar fraction) vs. 1/T in pure water and in the presence of varying nickel sulfate concentrations.

Table 3 : Estimated values of $\Delta H_{\text {sol }}(\mathrm{KJ} / \mathrm{mol})$, the enthalpy of dissolution of $\mathrm{AO}$ estimated from linear plots of $\ln C^{*}$ against $1 / T$ of experimental solubility data obtained with varying $\mathrm{NiSO}_{4}$ concentrations.

\begin{tabular}{|c|c|c|}
\hline $\mathrm{C}_{\text {imp }}\left(\mathrm{mol} / \mathrm{m}^{3}\right)$ & $\Delta \mathrm{H}_{\text {sol }}(\mathrm{kJ} / \mathrm{mol})$ & $\mathrm{R}^{2}$ \\
\hline 0 & 32.52 & 0.99 \\
\hline $610^{-6}$ & 31.31 & 1 \\
\hline $210^{-5}$ & 30.06 & 0.99 \\
\hline $410^{-5}$ & 26.43 & 0.99 \\
\hline
\end{tabular}

\section{Notions of inhibiting adsorption of impurities and residual supersaturation.}

\subsection{Experimental observation of supersaturation thresholds and inhibition effects}

After determining the corresponding solubility curves, supersaturation profiles were computed from the ATR FTIR concentration measurements performed during cooling crystallization operations in impure solvent. In order to better investigate the kinetics, the 
batch operations were also carried out with varying cooling rates ${ }^{1}$. Figure 8 shows two typical supersaturation vs. temperature profiles obtained with a cooling rate of $-20^{\circ} \mathrm{C} / \mathrm{h}$, for two different concentrations of impurities. Supersaturation was computed with respect to the actual solubility (i.e., with dissolved impurity):

$$
\sigma(t)=\frac{C(t)-C_{i m p}^{*}}{C_{i m p}^{*}}
$$

The relative uncertainty of the "measured" supersaturation was estimated to be of the order of $3 \%$. When compared to the crystallization advancement in pure solvent, the overall solute consumption is clearly slowed down so that the supersaturation remains high during the cooling process following the onset of primary nucleation. It should also be noted from Fig. 8 that the primary nucleation burst is delayed. The arrows indicate the maximal values of supersaturation corresponding to the so-called "limit of metastable zone". The supersaturation profiles exhibit the following maximal values measured during the primary nucleation peak: $\sigma_{\text {lim }}=0.4$ for $C_{i m p}=0.02 \mathrm{~mol} / \mathrm{L}$ and $\sigma_{\text {lim }}=0.22$ for $C_{i m p}=0.006 \mathrm{~mol} / \mathrm{L}$. The first nucleation burst is therefore delayed for increasing concentrations of impurities, which confirms the overall inhibition of the crystallization process. The average value of $\sigma_{\text {lim }}$ in pure water was about 0.2 for batch experiments performed with the cooling rate $d T / d t=-20^{\circ} \mathrm{C} / \mathrm{h}$ ${ }^{1}$. The enlargement of the metastable zone obtained with $C_{i m p}=0.006 \mathrm{~mol} / \mathrm{L}$ is thus negligible, despite the importance of the effect of the dissolved impurities on the overall concentration trajectory.

At the end of the batch process, a significant level of supersaturation remains after a 3-hours isothermal maturation stage. In order to check the reality of the crystallization stopping, the suspension was kept at $20^{\circ} \mathrm{C}$ for 30 hours. Figure 9 shows that the concentration goes on decreasing slowly before reaching its equilibrium value. Moreover, the equilibrium finally corresponds to the solubility measured with dissolved $\mathrm{NiSO}_{4}$. Three important points can be outlined from these observations. At the end of the batch cooling process, the crystallization seems to be stopped (i.e., the solute concentration does not seem to evolve any more, at the time scale of the batch process.) Rather than plotting $\sigma=f(T)$ in Fig. (8), plotting $\sigma=f(t)$ shows that the growth rate is not nil at the end of the batch process (i.e. during the final isothermal stage): the variations of the solute concentration suggest strong inhibition 
phenomena. The apparent steady-state supersaturation threshold characterizing the system (in the sense of inhibition models) requires a significant maturation time to be reached. It addition to these two observations, it should be outlined that the final supersaturation threshold coincides with the increase of solubility investigated above (i.e. the increase of solubility resulting from the presence of impurities in water/AO solution.) One could therefore conclude that the final supersaturation threshold is nil, provided we consider the supersaturation reference as defined with respect to the actual solubility (i.e., the solubility in impure solvent.)

From these results, the undesirable phenomenon referred to as a supersaturation threshold should be called into question. This is why the notion of residual supersaturation and its theoretical basis are now examined.

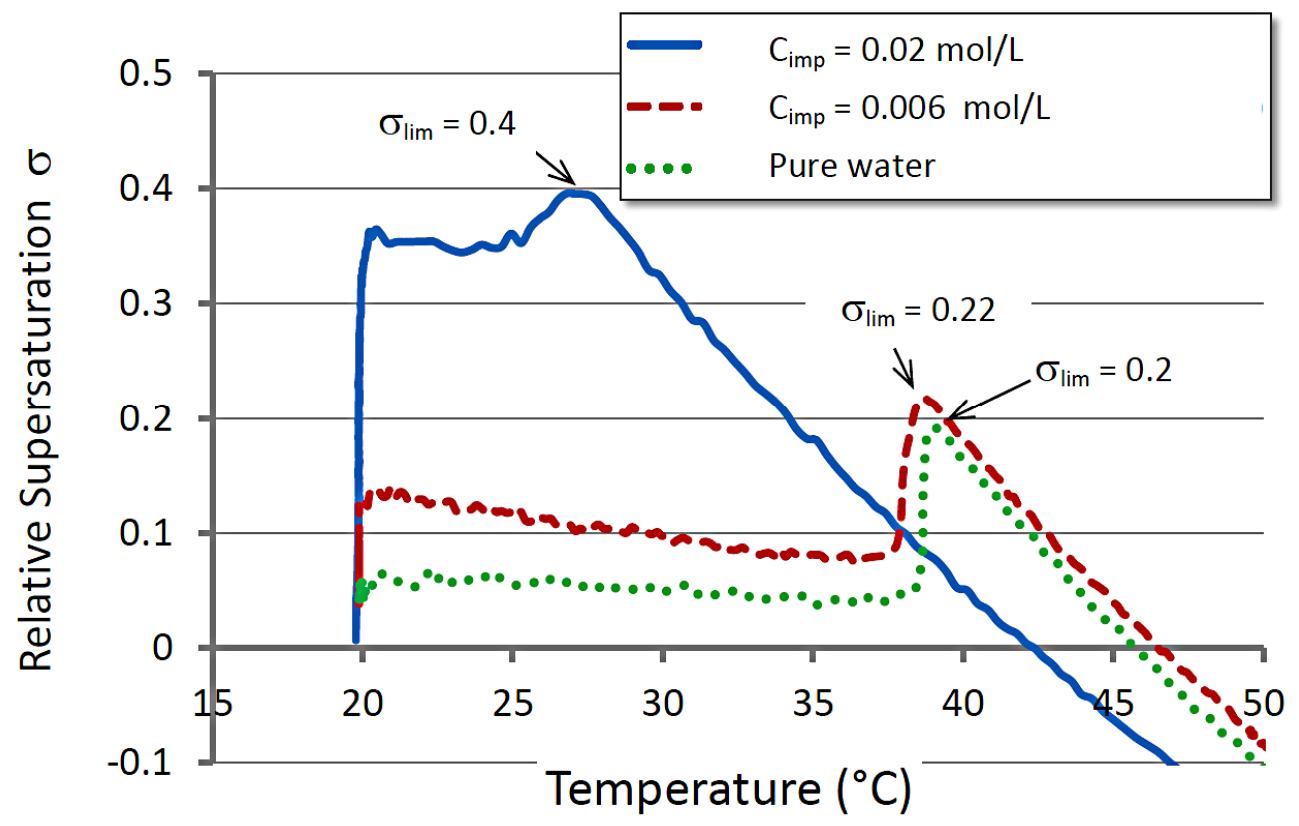

Figure 8 Typical supersaturation profiles measured during the cooling crystallization of $A O$ performed with a cooling rate of $-20^{\circ} \mathrm{C} / \mathrm{h}$, with different concentrations $C_{i m p}$ of nickel sulfate. 


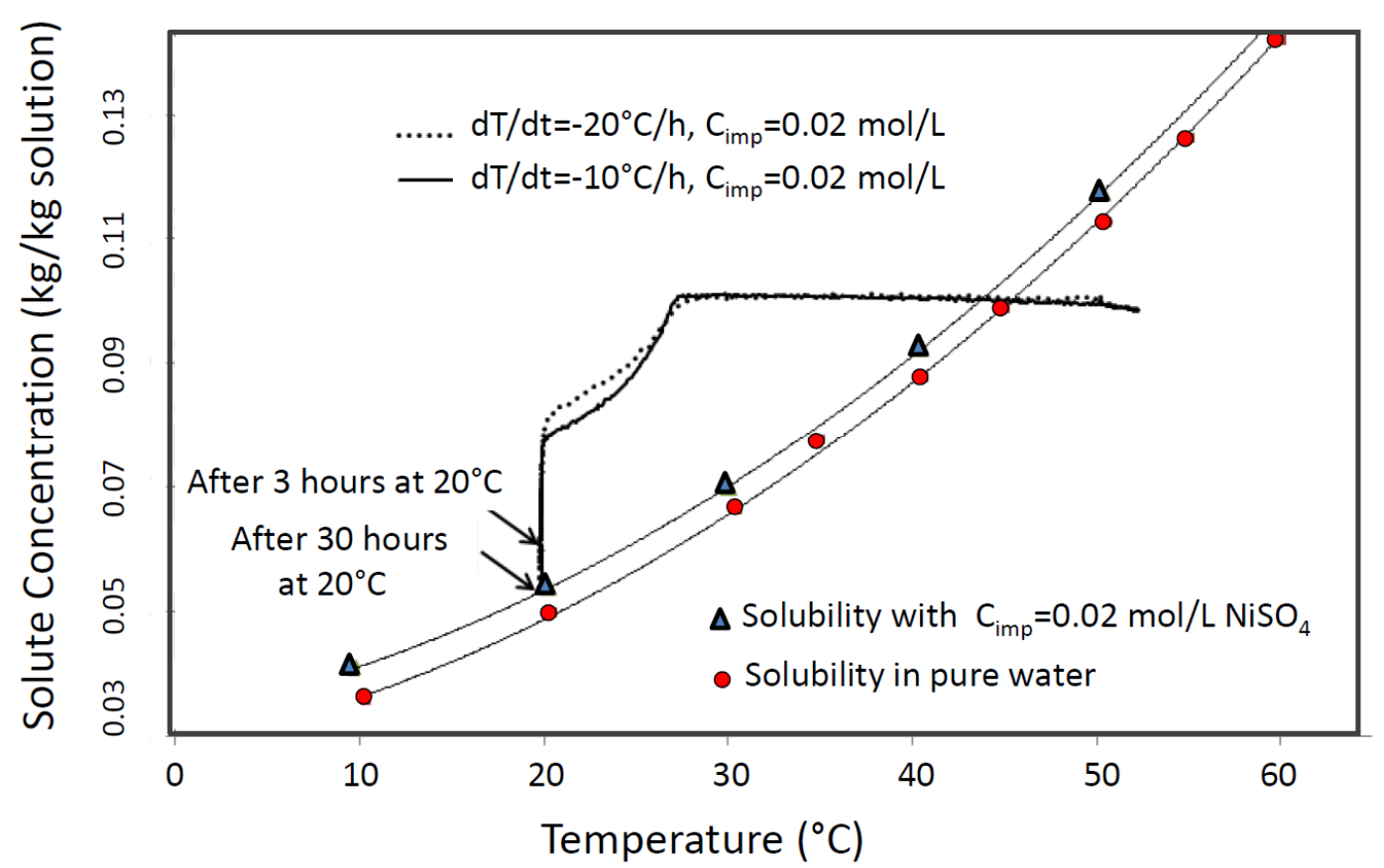

Figure 9. Solute concentration profiles measured during the cooling crystallization of $A O$ performed with 2 cooling rates $\left(\mathrm{dT} / \mathrm{dt}=-20\right.$ and $\left.-10^{\circ} \mathrm{C} / \mathrm{h}\right)$ and constant concentration of nickel sulfate $C_{\text {imp }}=0.02 \mathrm{~mol}^{-\mathrm{L}^{-1}}$.

The physics of the adsorption of impurity species was studied using molecular simulation modeling which was expected to allow better understanding of the interactions between the AO crystal and adsorbates. In particular, as presented below, molecular simulation allowed estimating the adsorption energy of $\mathrm{Ni}$ and $\mathrm{SO}_{4}$ ions. The results were then compared to the experimental data obtained above.

It should firstly be outlined that several papers dealt with the inhibiting effect of the adsorption of $\mathrm{Ni}^{2+}$ during the growth of $\mathrm{AO}$ crystals while the possible adsorption of $\mathrm{SO}_{4}{ }^{2-}$ was not clearly evaluated in the past. Actually, dynamic simulation studies performed during this work suggested that sulfate ions, to a lesser extent than $\mathrm{Ni}^{2+}$, could also play a role in the inhibition of the crystallization of $\mathrm{AO}$. To evaluate this assumption, cooling solution crystallization experiments were performed in the presence of $0.0019 \mathrm{~mol} . \mathrm{L}^{-1}$ nickel sulfate and ammonium sulfate, with a cooling rate of $-30^{\circ} \mathrm{C} / \mathrm{h}$. Some pictures taken during these two experiments are presented in comparison with $\mathrm{AO}$ suspensions obtained in pure water 
(Fig.10a vs. 10b). The deterioration of the crystal surfaces and shapes, and the presence of crystal fragments in Fig. 11b suggest that the presence of sulfate ions also affects the overall crystal generation process. Growth inhibition caused by the presence of sulfate ions was also confirmed thanks to ATR FTIR AO concentration measurements during batch cooling experiments which are not presented here, and by further related experimental observations (see Fig. 9). The likely adsorption of both $\mathrm{Ni}^{2+}$ and $\mathrm{SO}_{4}{ }^{2-}$ ions on $\mathrm{AO}$ crystal faces was also confirmed by the molecular modeling simulations presented in the sequel.

The separate effect of nickel and sulfate ions was also evaluated through monitoring batch cooling crystallization experiments performed with $0.0019 \mathrm{~mol} / \mathrm{L}$ dissolved $\mathrm{NiCl}_{2}$ and $\mathrm{NiSO}_{4}$. The corresponding solute concentration profiles are presented in Fig. 11 also recalling the time variations of concentration measured in pure water after applying identical operating conditions. The experiments demonstrate a stronger inhibiting effect of $\mathrm{Cl}^{-}$than $\mathrm{SO}_{4}{ }^{2-}$ but do not allow comparing the inhibiting effect of the adsorption of $\mathrm{Ni}^{2+}$ and $\mathrm{SO}_{4}{ }^{2-}$. It can therefore be assumed that the overall growth inhibition process results from a competitive inhibiting adsorption of the dissolved ionic species during the crystallization of $\mathrm{AO}$.

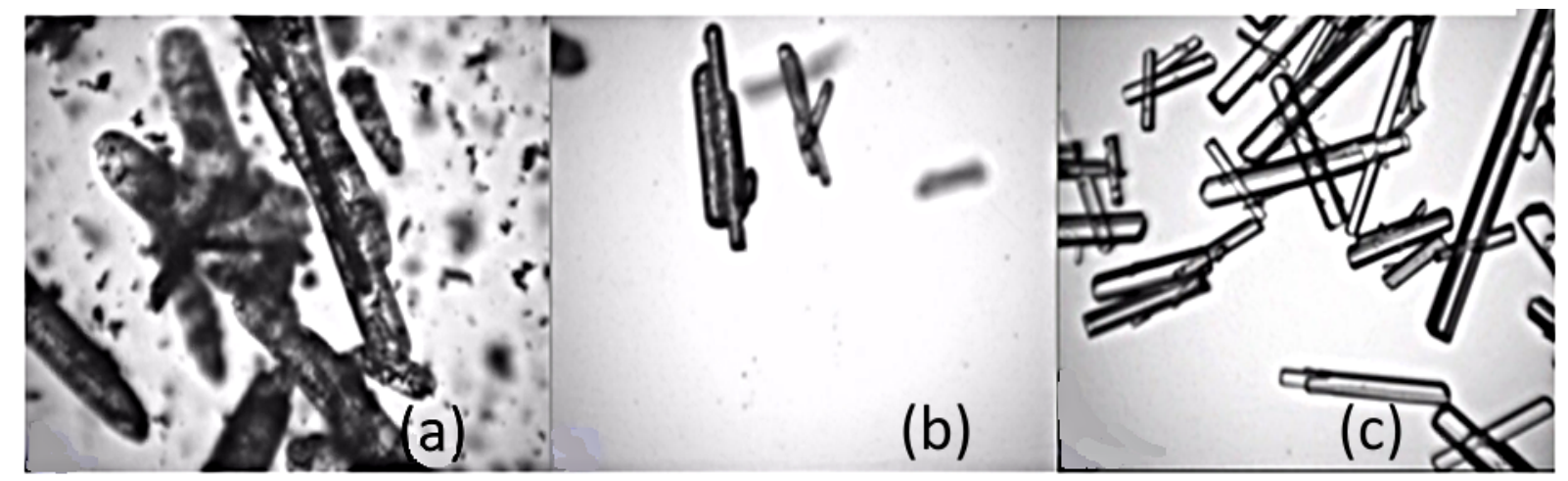

Figure 10. Pictures taken during the cooling crystallization of $A O$ performed with a cooling rate of $-30^{\circ} \mathrm{C} / \mathrm{h}$, in the presence of $0.0019 \mathrm{~mol} / \mathrm{L}$ (a) Nickel sulfate; (b) Ammonium sulfate, and in (c) Pure water. 


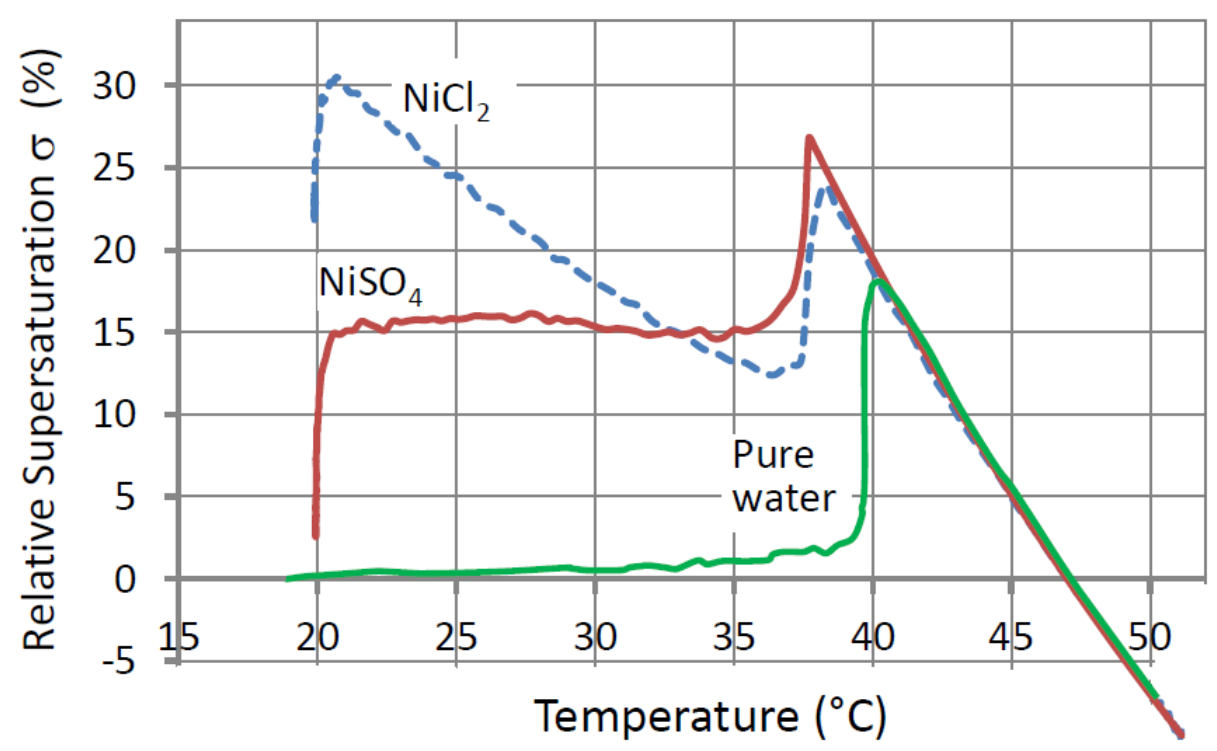

Figure 11. Comparison between the concentration profiles measured during the $A O$ cooling crystallization performed at a cooling rate of $-30^{\circ} \mathrm{C} / \mathrm{h}$ in the presence of $0.0019 \mathrm{~mol} . \mathrm{L}^{-1}$ nickel chloride and nickel sulfate.

\subsection{Molecular modeling simulation of the adsorption of ionic species on AO crystal faces.}

To compare the interaction between $\mathrm{AO}$ crystal faces and both $\mathrm{Ni}^{2+}$ and $\mathrm{SO}_{4}{ }^{2-}$ ions, the competitive adsorption occurring on the different $A O$ crystal faces through was evaluated thanks to molecular modeling simulations. First of all, the theory of attachment energies predicts an equilibrium AO crystal structure which is rather close to the structure described in the literature ${ }^{22,23}$, but the energy values were "adapted" so as to improve the fit between the equilibrium and experimental crystal shape. The simulation was carried out with 4000 atoms, with a cut-off radius of $13 \AA$. With respect to their tendency to attract ions, the $\{010\}$ and $\{110\}$ faces present a particular interest. The $\{010\}$ face is rather steep with sharp edges of exposed ammonium species. The face contains electropositive wells that can interact with $\mathrm{SO}_{4}{ }^{2-}$ ions and electronegative edges that can interact with $\mathrm{Ni}^{2+}$. The $\{110\}$ face is smoother than the $\{010\}$, with edges favorable to the adsorption of $\mathrm{SO}_{4}{ }^{2-}$. For the sake of conciseness, the representation of the crystal structure will not be given here. 
Additional molecular simulations were again performed to bring information about the possible adsorption of ionic species. As far as the $\{101\}$ face is concerned, the adsorbed $\mathrm{Ni}$ is linked through 4 dative covalent bond, with three neighbor oxalate ions, and one oxygen of the water molecule. However, in view of the deeper position of adsorbed $\mathrm{Ni}$, the ammonium ions are more facing to the outside. Sulfate ions can also interact with two ammonium ions through electrostatic bonds, and through weak hydrogen bonds with two oxygen atoms of neighboring water molecules. Owing to its small size and to its interactions with the environment, $\mathrm{Ni}^{2+}$ could incorporate the crystal lattice, at least at a shallow depth, while sulfate would rather adsorb at the surface. A representation of the structure of the $\{101\}$ face and of its interactions with nickel and sulfate species is presented in Fig.14. Due to the lack of place, the representation of the $\{110\}$ face and of its interactions is not presented in this paper. Regarding the $\{110\}$ face, $\mathrm{Ni}^{2+}$ ions interact through dative covalent bonds with 3 oxygens of the oxalate groups and one oxygen of the water molecule located above. In a fashion similar to the $\{010\}$ face, $\mathrm{SO}_{4}{ }^{2-}$ can adsorb on the $\{110\}$ face. Both nickel and sulfate ions are therefore likely to restrain the growth of $\mathrm{AO}$ crystal through adsorption, and some incorporation of $\mathrm{Ni}^{2+}$ through the $\{010\}$ face cannot be excluded.

Molecular simulation was also applied to the systems $\mathrm{AO} / \mathrm{NiSO}_{4}$ for estimating the adsorption energies of the two impurity ionic species on the different crystal faces. The main computation results are presented in Table 4. When the difference between the attachment energy and the adsorption energy of a given specie on a given surface is positive, the adsorbed specie has low impact of the crystal growth process. In contrast, when the difference is negative, the impurity slows down or even blocks the face growth, leading to a spreading of the latter face. Weaker differences of energies induce increased competition between the solute molecules and impurities, which can cause significant changes in the crystal shape. As explained above, the $\{010\}$ face is mostly affected by the presence of impurities and, to a lesser extent, so is the $\{110\}$ face. The Stranski-Krastanov model, which mainly applies to organic crystals where Van der Waals bonds predominate, was used for the computations. However, as electrostatic energies are mainly involved in the growth of $\mathrm{AO}$, even though adsorption energies contribute significantly to the growth, it was important to evaluate the relevance of the computations. Such validation was carried out through the 
comparison between the calculated total energy of the crystal and its experimental estimate.

Using GenMol${ }^{\circledR}$, the calculated crystal energy is $-443 \mathrm{~kJ} \mathrm{~mol}^{-1}$. The experimental evaluation of the crystal energy was also tried using DSC (Differential Scanning Calorimetry). Unfortunately, in the case of $A O$, the technique is not fully reliable. Indeed, AO starts to decompose at $70^{\circ} \mathrm{C}$, until $200^{\circ} \mathrm{C}$, while water starts evaporating, with a maximal evaporation rate observed around $115^{\circ} \mathrm{C}$. Between $200^{\circ} \mathrm{C}-235^{\circ} \mathrm{C}$ and $235^{\circ} \mathrm{C}-300^{\circ} \mathrm{C}$, melting followed by vaporization and concomitant decomposition are observed. Due to the simultaneity of the involved thermal phenomena, estimating the energy of the AO crystals is therefore rather hazardous. The sublimation energy was still assessed assuming that the sublimation energy is given by the sum of the energy of vaporization of structural water and of the AO melting/vaporization energy. A "pseudo sublimation energy" was thus evaluated to be 229 $\mathrm{kJ} . \mathrm{mol}^{-1}$. Considering that the crystal energy is of the order of twice the sublimation energy, it can therefore reasonably be concluded that the adsorption energies evaluated using GenMol ${ }^{\circledR}$ are acceptable.

Table 4 : Computed adsorption energies (in $\mathrm{kJ} / \mathrm{mol}$ ) of sulfate and nickel species on the crystal faces subject to interactions with both impurities..

\begin{tabular}{cccccc}
\hline $\begin{array}{c}\text { Crystal } \\
\text { Face }\end{array}$ & $\begin{array}{c}\text { Attachement } \\
\text { Energy }\end{array}$ & $\begin{array}{c}\mathrm{SO}_{4}^{-2} \text { Adsorption } \\
\text { Energy }\end{array}$ & $\begin{array}{c}\mathrm{Ni}^{2+} \text { Adsorption } \\
\text { Energy }\end{array}$ & $\begin{array}{c}\left(\mathrm{E}_{\text {att }}-\mathrm{E}_{\text {ads }}\right) \\
\mathrm{SO}^{-2}\end{array}$ & $\begin{array}{c}\left(\mathrm{E}_{\text {att }}-\mathrm{E}_{\text {ads }}\right) \\
\mathrm{Ni}^{2+}\end{array}$ \\
\hline 110 & -20.5 & -26.85 & -23.2 & -6.4 & -2.7 \\
\hline 010 & -0.5 & -20.39 & -23.7 & -20.9 & -24.2 \\
\hline
\end{tabular}


(a)

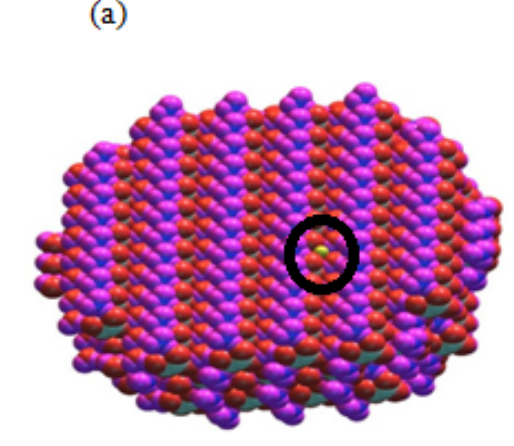

(b)

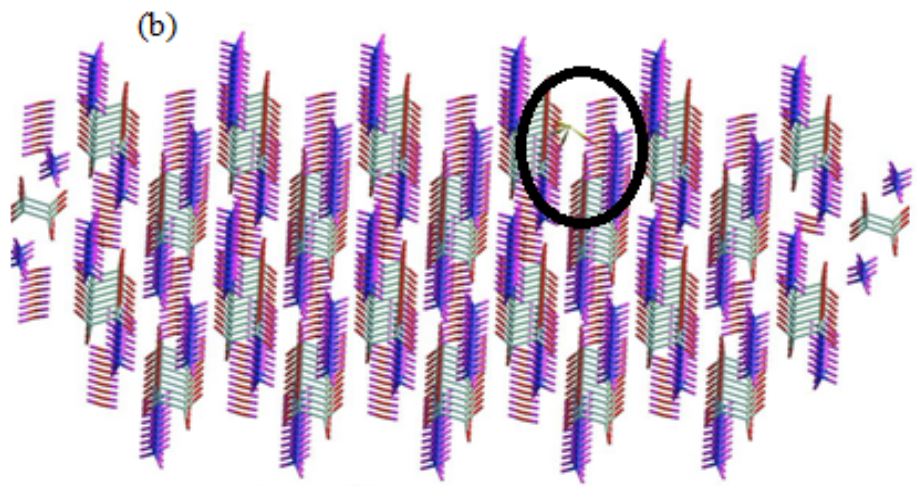

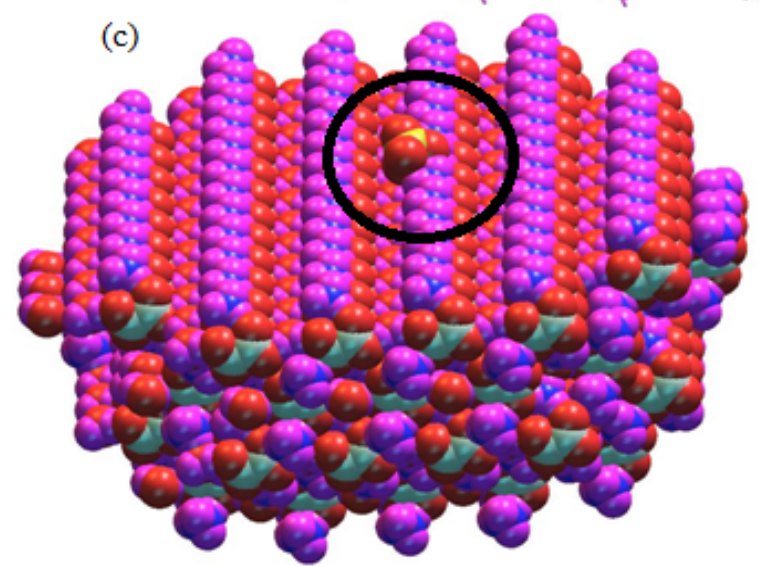

Figure 12: (a) Representation of the $\{010\} \mathrm{AO}$ face in the presence of $\mathrm{Ni}^{2+}$. For the sake of visibility the atom of nickel was expanded 3 times. (b) Stick representation of the same face in the presence of $\mathrm{SO}_{4}{ }^{2-}$. (c) Representation of the $\{010\}$ face with adsorbed sulfate anion.

\section{Growth inhibition models and supersaturation thresholds}

Several models describing the inhibition of crystal growth by impurities were proposed in the literature ${ }^{24,25,26,3}$. According to Cabrera and Vermilyea ${ }^{27}$, the elementary growth steps are hindered by the adsorption of impurity species which results in the socalled "pinning effect". When the impurity spacing becomes narrower than the critical radius of step curvature, the model predicts the cancellation of the growth rate. As a consequence, when supersaturation $\sigma$ defined by Eq.(7) falls below a critical threshold $\sigma_{c}$, the pinning effect leads to a "dead zone" where the growth steps are stopped. Cabrera and Vermylyea model was further reexamined by Kubota and Mullin who considered that the coverage of the crystal surface, expressed thanks to Langmuir's adsorption theory, should be corrected by the efficiency parameter $\alpha$ introduced in the following Eq.(8). To allow further crystal growth, the growth-step has to circumvent the adsorbed impurity, which obviously reduces the overall growth rate. Several models describing such "pinning mechanism" were early 
described and many convincing experimental observations of the pinning mechanism were reported in the literature, notably thanks to the use of advanced imaging techniques such as AFM (Atomic Force Microscopy, see e.g. ${ }^{28,29,30}$ ).

According to Cabrera-Vermylyea and KM theory, the ratio $\Gamma$ between the step velocities in pure solvent $\left(u_{0}\right)$ and in the presence of dissolved impurity $(u)$ is expressed as a function of the coverage fraction of inhibited active sites $\theta$ and of an overall effectiveness factor $\alpha$ :

$$
\Gamma=\frac{u}{u_{0}}=1-\left(\frac{\gamma a}{k T \sigma L}\right) \theta=1-\alpha \theta=1-\left(\frac{\omega}{T \sigma}\right) \theta^{n}
$$

where $\gamma$ is the edge free energy, $a$ is the size of the growth unit, $T$ is the absolute temperature, $k$ is the Boltzmann constant, $\theta$ is the coverage fraction of active growing crystal surface by adsorbed impurities and $L$ is the average distance between the adsorbed impurity species. Exponent $n$ depends on the hindered active site: $n=1$ when the adsorption of impurity occurs at kink sites and $n=1 / 2$ when random surface active sites on terrace are concerned. In the sequel, $\mathrm{n}$ was set to 1 .

Assuming that the overall growth rate $\mathrm{G}$ of a crystal is proportional to the step velocity $u$, Eq.(8) yields:

$$
G(t)=G_{0}(t)(1-\alpha \theta)
$$

According to Eq.(8), $\alpha$ does not depend on properties of the crystal only, but also on temperature and supersaturation ${ }^{2}$. When the adsorption process reaches its steady-state, the equilibrium coverage is referred to as $\theta *$. According to $\mathrm{KM}$ Model ${ }^{31,32}$ the equilibrium coverage of the growing surface is simply estimated thanks to Langmuir adsorption theory where $K$ is the Langmuir adsorption constant:

$$
\theta^{*}=\left(\frac{K C_{i m p}}{1+K C_{i m p}}\right)
$$

In the present case, both $\mathrm{Ni}$ and $\mathrm{SO}_{4}$ species are likely to adsorb on active kink sites, and to hinder the growth of $\mathrm{AO}$. The overall coverage of growing surface by the two ionic impurity species accounts for the two different adsorption constants and for the concentration of the 
two impurity species ${ }^{2}$. Assuming negligible incorporation of nickel sulfate during the crystallization and equality between the two ionic concentrations we get the following equation expressing the competitive adsorption of the two ionic species:

$$
\begin{aligned}
\theta^{*} & =\left(1-\theta_{\mathrm{Ni}}\right)\left(\frac{K_{\mathrm{Ni}} C_{\mathrm{Ni}}}{1+K_{\mathrm{Ni}} C_{\mathrm{Ni}}}\right)+\left(1-\theta_{\mathrm{SO}_{4}}\right)\left(\frac{K_{\mathrm{SO}_{4}} C_{\mathrm{SO}_{4}}}{1+K_{\mathrm{SO}_{4}} C_{S_{4}}}\right) \\
& =\left[\left(1-\theta_{\mathrm{Ni}}\right)\left(\frac{K_{\mathrm{Ni}}}{1+K_{N i} C_{i m p}}\right)+\left(1-\theta_{\mathrm{SO}_{4}}\right)\left(\frac{K_{S_{4}}}{1+K_{S_{4}} C_{i m p}}\right)\right] C_{i m p}
\end{aligned}
$$

Average values of the adsorption energies of nickel and sulfate displayed given in Table 4, make it possible to calculate the adsorption constants:

$$
K_{\mathrm{NiorSO} 4}=\exp \left(\frac{E_{a d s, \mathrm{NiorSO} 4}}{\mathrm{kT}}\right)
$$

The coverage fractions of $\mathrm{Ni}$ and $\mathrm{SO}_{4}$ impurities was computed using Eqs.(11) and (12), for an impurity concentration of $0.02 \mathrm{~mol}^{-1}$. The results are displayed in Figure (13). The adsorption of sulfate cannot be neglected, even though $\mathrm{Ni}^{2+}$ is the main adsorbed impurity.

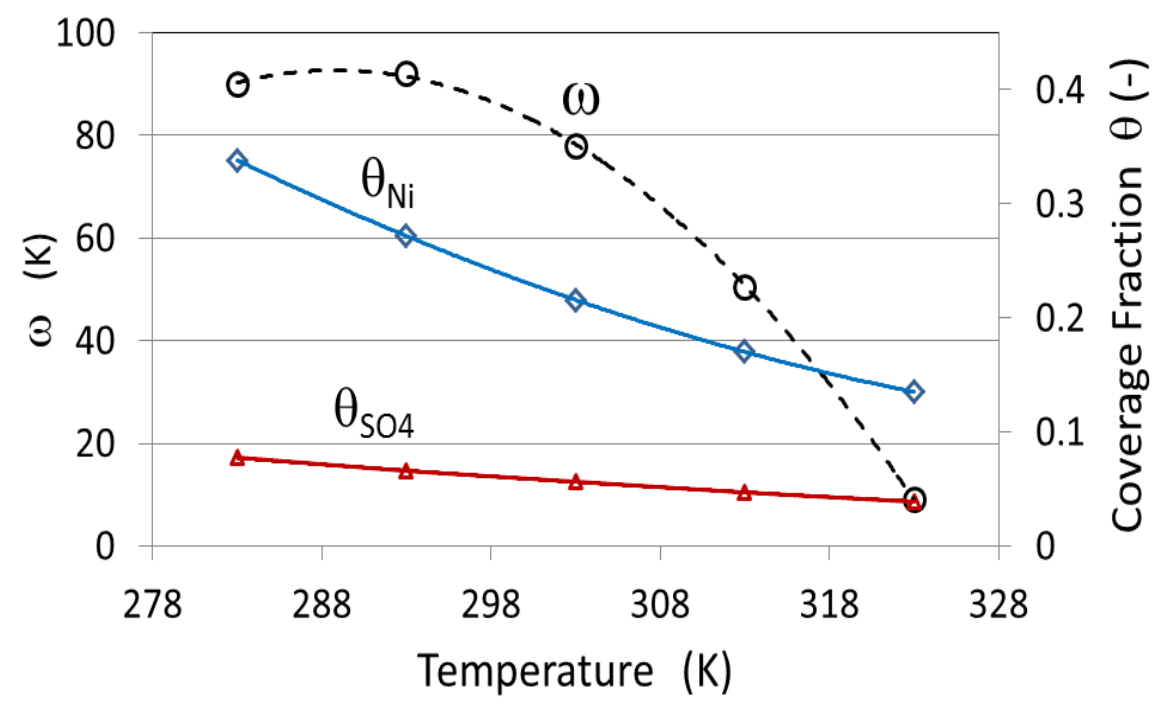

Figure 13. Estimated temperature variations of parameter $\omega$ and of the coverage fractions of $\mathrm{Ni}$ and $\mathrm{SO}_{4}$ species for an impurity concentration $\mathrm{C}_{\mathrm{NisO}}=0.02 \mathrm{~mol}^{-\mathrm{L}^{-1}}$.

Now, according to Eqs. (8) and (9), the growth rate is cancelled (i.e., G=0) when the supersaturation falls below $\sigma_{c}$ such that: 


$$
\sigma_{c}=\frac{\gamma a}{k T L} \theta^{*}=\frac{\omega}{T} \theta^{*}
$$

As already outlined, many studies dealing with the effect of impurities on crystallization kinetics consider the solubility of the pure system as the actual solubility, which is questionable. In particular, such an assumption implicitly means that the equilibrium concentration measured in the presence of impurities should actually be considered as a threshold of supersaturation. Assuming that the difference $\Delta C_{i m p}^{*}=C_{i m p}^{*}-C_{0}^{*}$, computed from the solubility data displayed in Fig.3, can be regarded as the critical supersaturation $\sigma_{c}$, the critical supersaturation should amount to the following ratio:

$$
\sigma_{c}=\Delta C_{i m p}^{*} / C_{0}^{*}
$$

Combining Eqs.(11) to (13) and assuming that the supersaturation threshold is given by Eq.(13) allows estimating $\omega$ as a function of temperature:

$$
\omega=\frac{\gamma a}{k L}=\frac{T \sigma_{c}}{\theta^{*}}=\frac{T \Delta C_{i m p}^{*}}{C_{0}^{*}\left[\left(1-\theta_{N i}\right)\left(\frac{K_{N i}}{1+K_{N i} C_{i m p}}\right)+\left(1-\theta_{S O_{4}}\right)\left(\frac{K_{S O_{4}}}{1+K_{S O_{4}} C_{i m p}}\right)\right] C_{i m p}}
$$

A plot of $\omega=f(T)$ is displayed in Fig.13 for $C_{i m p}=0.02$ mol. $\mathrm{L}^{-1}$. The variations exhibit a very significant decrease for increasing temperature. Knowing that the liquid-solid interfacial tension is expected to increase for increasing temperature ${ }^{33,34}$, the results suggest that the average distance between the active sites $L$ increases very strongly with temperature, which is quite unlikely. Furthermore, an estimate of $\omega$ was proposed in a recent paper ${ }^{35}$ reporting partial results about the dynamic population equation balance modeling of the crystallization of $\mathrm{AO}$ in the presence of $0.006 \mathrm{~mol} / \mathrm{L}$ dissolved $\mathrm{NiSO}_{4}$. In this paper, $\omega$ was assumed constant and, in the average, found to be equal to $1080 \mathrm{~K}$. This latter value was obtained through parameter optimization based on data acquired during batch cooling experiments (i.e. using supersaturation profiles like the ones in Figs 8 and 9). However, $\omega$ was obtained without accounting for the adsorption of sulfate and no estimate of the adsorption energy of $\mathrm{Ni}^{2+}$ was used. Other unpublished estimates accounting for the adsorption of both impurity species and using the estimated values of the adsorption energy 
in Table 4 were further obtained. It was finally found that, in the average, $\omega \cong 350 \mathrm{~K}$. This estimate ${ }^{12}$ is probably more reliable than the previous value $\omega=1080 \mathrm{~K}$ since it was computed from several experimental datasets and led to satisfactory simulation of the whole crystallization process..

\section{Discussion.}

Most studies dealing with the dynamic modeling of inhibiting effects of impurities on crystal growth remain rather vague about the appropriate definition of the solubility $C_{i m p}^{*}$ in the presence of impurities, and about its use for computing supersaturation in impure solvents. As already outlined, this vagueness is all the more surprising that possible drifts of the final solute concentration during crystallization processes have an obvious effect on the yield of industrial batch operations and, consequently, on their economical performances. Indeed, apart from the problem of possible changes of "crystal quality" through the incorporation of foreign species, the presence of impurities affects the solution speciation and is thus expected to affect the solubility $C_{0}^{*}$ of the pure system. In this context two different stances can be adopted for analyzing the growth inhibition problem even though both viewpoints can hardly be considered as compatible. On the one hand, one can assume that apparent changes of solubility in impure solvent would result from supersaturation thresholds described by inhibition models (e.g. Kubota-Mullin's pining mechanism model, Martins competitive adsorption model, Doherty model of molecular imposters ...) Consistently with this first point of view, the definition of solubility and supersaturation should be unchanged with respect to the case of the pure system. On the other hand, it seems logical to consider that the actual solubility in impure solvent should be the appropriate reference for computing supersaturation. For increasing concentration of impurities, supersaturation would therefore be lowered when the solubility increases in the presence of dissolved impurities.

It is not straightforward to be definitive about the correct viewpoint to adopt in the case of the $\mathrm{AO} / \mathrm{NISO}_{4} /$ water system investigated here. From a thermodynamic viewpoint, while no incorporation of impurities in the crystal lattice was observed, it is clear that the speciation 
of the liquid phase is changed by dissolved impurities, as well as the properties of the liquidsolid interface. It is therefore consistent to observe drifts of the solubility in the presence of dissolved impurities. In such conditions, there is no logical reason to go on considering the solubility in pure solvent as a correct reference. In other words, it is difficult to support the idea that the difference $\Delta C_{i m p}=C_{i m p}^{*}-C_{0}^{*}$ is a "true" supersaturation threshold, as predicted by inhibition theories. Moreover, as outlined in the experimental part of this paper, different solubility curves of impure systems were determined through both cooling and heating procedures. The fact that the "heating" and "cooling" curves coincide suggests that the solute-solvent system returns to a "true" equilibrium in both cases. It should also be noted, even though it was not fully conclusive, that the speciation study presented above allowed explaining the main trends of the observed drifts of solubility, in particular as a function of temperature. This argues again in favor of considering that each solute-solvent-impurity system is characterized by its own solubility curve and, consequently, that the appropriate definition of supersaturation in impure systems should refer to the impurity-concentration dependent solubility (i.e., not to the unique curve obtained in pure solvent).

Moreover, the assumption that $\Delta C_{i m p}$ is a supersaturation barrier was analyzed in the light of Kubota-Mullin pinning model. This analysis was based on estimates of the adsorption energy of nickel and sulfate impurity species. Identifying $\Delta C_{i m p}$ to $\sigma_{c}$ (i.e., the critical supersaturation defined by the growth inhibition model) allowed estimating $\omega=\gamma a / k L$, a lumped parameter characterizing the crystal/solution system. Compared to estimates of $\omega$ obtained during a more thorough unpublished study, the estimates of $\omega$ seem to be significantly underestimated, which suggests that $\Delta C_{i m p}$ should not be considered as a supersaturation threshold.

\section{Conclusions and perspectives.}

The present study of the ternary $\mathrm{AO} / \mathrm{NiSO}_{4} /$ water solute/impurity/solvent system aims at investigating the inhibition effects of impurities on the development of batch cooling crystallization processes. New experimental and theoretical results demonstrate unambiguously the inhibition of the growth of crystals by dissolved impurities. In such conditions, the transient behavior of the crystallization process appears to be rather 
complex and, before analyzing and modeling the nucleation and growth kinetics involved, it was first necessary to characterize the equilibrium features of the system.

As a wide as possible range of techniques was applied to analyze the significance of residual supersaturation thresholds observed at the end of batch cooling crystallization experiments performed in the presence of $\mathrm{NiSO}_{4}$ dissolved impurities: dynamic continuous and steadystate multi-step equilibrium concentration measurements, calorimetric analysis, solid state analysis (Raman, XRS, etc.), and molecular simulation modeling.

The quantitative information provided thanks to the various experimental and theoretical approaches applied during this work was put in contrast with Kubota-Mullin impurity adsorption theory. The main conclusion drawn from the latter comparison is that increases of final equilibrium concentrations with increasing impurity concentrations should rather be attributed to solubility drifts than to supersaturation thresholds (in the sense of KubotaMullin pinning model)

This latter conclusion is somewhat unexpected because, in the present case-study, it seems to call into question the notion of "supersaturation thresholds" developed in the framework of growth-inhibiting adsorption mechanisms. We thus suggest that most papers dealing with the effect of impurities during solution crystallization processes present blind spots sometimes erroneous interpretations- about the right way of defining supersaturation. In the presence of impurities, using the right reference solubility and defining correctly supersaturation requires accounting for solubility variations. This is why we finally propose that no reliable study dealing with the effect of impurities on the kinetics of crystallization should be carried out without a rigorous preliminary evaluation of the variations of solubility in impure solvents.

\section{Acknowledgements:}

We greatly acknowledge the French Research Agency ANR (Agence Nationale de la Recherche) for the support granted to the "white project" IPAPI (Improving the Properties of Active Pharmaceutical Ingredients), ref.07-BLAN-0183.

We also thank the following researchers for their very kind and valuable assistance: Professor K. SANGWAL for his invaluable help and wise advices about the manuscript and Doctor Gerard PEPE (Research Director at UPR-CNRS 3118) for his expertise and his contribution to the molecular simulation study. 


\section{References.}

(1) Gherras, N. ; Fevotte, G. On the use of process analytical technologies and population balance equations for the estimation of crystallization kinetics. A case study. AIChE J., 2012, 58, 2650-2664.

(2) Sangwal, K. Additives and Crystallization Processes: From Fundamentals to Applications. (Wiley-Blackwell (an imprint of John Wiley \& Sons Ltd), 2007).

(3) Kubota, N. Effect of Impurities on the Growth Kinetics of Crystals. Crystal Research and Technology, 2001, 36, 749-769.

(4) Heijna, M. C. R., Van Enckevort, W. J. P. \& Vlieg, E. Growth inhibition of protein crystals: A study of lysozyme polymorphs. Crystal Growth and Design , 2008, 8, 270-274.

(5) Bhamidi, V., Hanson, B. L., Edmundson, A., Skrzypczak-Jankun, E. \& Schall, C. The influence of a homologous protein impurity on lysozyme crystal growth. J. Crystal Growth, 1999, 204, 542-552.

(6) Halberstein, R. A. in Studies in Natural Products Chemistry (Atta-ur-Rahman) 37, 1-41 (Elsevier, 2012).

(7) Kalin, M. Passive mine water treatment: the correct approach? Ecological Engineering , 2004, 22, 299-304.

(8) Weijnen, M. P. C. ; van Rosmalen, G. M. ; Bennema, P. The adsorption of additives at the gypsum crystal surface: A theoretical approach: II. Determination of the surface coverage required for growth inhibition. J. Crystal Growth, 1987, 82, 528-542.

(9) Bauer, M., de Leede, L. \& Van Der Waart, M. Purity as an issue in pharmaceutical research and development. Eur. J. Pharmaceutical Sciences, 1998, 6, 331-335.

(10) Sangwal, K. ; Mielniczek-Brzóska, E. Effect of impurities on metastable zone width for the growth of ammonium oxalate monohydrate crystals from aqueous solutions. $J$. Crystal Growth, 2004, 267, 662-675.

(11) Sangwal, K. ; Mielniczek-Brzoska, E. Effect of cationic impurities on solubility and crystal growth processes of ammonium oxalate monohydrate: Role of formation of metaloxalate complexes. Crystal Res. and Technol. , 2007, 531-543. 
(12) Gherras, N. Etude expérimentale et modélisation par bilans de populations des cinétiques de nucléation et de croissance d'opérations discontinues de cristallisation par refroidissement en absence et en présence d'impuretés (in french) 2011.

(13) Févotte, G. New perspectives for the on-line monitoring of pharmaceutical crystallization processes using in situ infrared spectroscopy. Int J Pharm, 2002, 241, 263-278.

(14) Menczel, B., Apelblat, A. \& Korin, E. The molar enthalpies of solution and solubilities of ammonium, sodium and potassium oxalates in water. The Journal of Chemical Thermodynamics , 2004, 36, 41-44.

(15) Seidell, A. Solubilities of Inorganic and Metal Organic Compounds. Third edition. J. Chem. Educ., 1953.

(16) Tanger, J.; Helgeson, H. Calculation of the Thermodynamic and TransportProperties of Aqueous Species at High-Pressures and Temperatures - Revised Equations of State for the Standard Partial Molal Properties of Ions and Electrolytes. Am. J. Sci. 1988, 288, $19-98$.

(17) Shock, E. Organic-Acids in Hydrothermal Solutions - Standard Molal Thermodynamic Properties of Carboxylic-Acids and Estimates of Dissociation-Constants. Am. J. Sci. 1995, 295, 496-580.

(18) Prapaipong, P., Shock, E. L. \& Koretsky, C. M. Metal-organic complexes in geochemical processes: Temperature dependence of the standard thermodynamic properties of aqueous complexes between metal cations and dicarboxylate ligands. Geochim. Cosmochim. Acta, 1999, 63, 2547-2577.

(19) Samson, E., Lemaire, G., Marchand, J. \& Beaudoin, J. J. Modeling chemical activity effects in strong ionic solutions. Comput. Mater. Sci. 1999, 15, 285-294.

(20) Mullin, J. W. Crystallization. Butterworth-Heinemann, 2001.

(21) Nyvlt, J. ; Ulrich, J. Admixtures in Crystallization. Wiley-VCH, 1995.

(22) Küppers, H. Anisotropy of thermal expansion of ammonium and potassium Oxalates. Zeitschrift für Kristallographie, 1974, 140, 393-398.

(23) Küppers, H. The crystal structure of ammonium hydrogen oxalate hemihydrate. Acta Crystallographica Section B Structural Crystallography and Crystal Chemistry, 1973, $29,318-327$. 
(24) Sizemore, J. P. \& Doherty, M. F. A New Model for the Effect of Molecular Imposters on the Shape of Faceted Molecular Crystals. Crystal growth \& des., 2009, 9, 26372645.

(25) Martins, P. M., Rocha, F. A. \& Rein, P. The Influence of Impurities on the Crystal Growth Kinetics According to a Competitive Adsorption Model. Crystal Growth \& Des. 2006, 6, 2814-2821.

(26) Martins, P. M., Rocha, F., Damas, A. M. \& Rein, P. Unsteady-state inhibition of crystal growth caused by solution impurities. CrystEngComm, 2011, 13, 1103.

(27) Cabrera, N. \& Vermilyea, D. Growth of crystals from solution. Growth and Perfection of Crystals, 1958, 393-408.

(28) Thomas, T. N., Land, T. A., Johnson, M. \& Casey, W. H. Molecular properties of adsorbates that affect the growth kinetics of archerite (KDP). J. Colloid Interface Sci. 2004, $280,18-26$.

(29) Ristic, R. I. ; DeYoreo, J. J. ; Chew, C. M. Does Impurity-Induced Step-Bunching Invalidate Key Assumptions of the Cabrera-Vermilyea Model? Crystal Growth \& Design 2008, 8, 1119-1122.

(30) Weaver, M. L.; Qui, S.R.; Hoyer, J.R. ; Casey, W.H. et al. Inhibition of calcium oxalate monohydrate growth by citrate and the effect of the background electrolyte. J. Crystal Growth, 2007, 306, 135-145.

(31) Kubota, N. ; Mullin, J. W. A kinetic model for crystal growth from aqueous solution in the presence of impurity. Journal of crystal growth, 1995, 152, 203-208.

(32) Kubota, N., Yokota, M. \& Mullin, J. W. Supersaturation dependence of crystal growth in solutions in the presence of impurity. J. Crystal Growth, 1997, 182, 86-94.

(33) Mersmann. Crystallization Technology Handbook. CRC Press, 2001.

(34) Spaepen, F. The temperature dependence of the crystal-melt interfacial tension: a simple model. Materials Science and Engineering: A, 1994, 178, 15-18.

(35) Fevotte, G. ; Gherras, N. On Multiple Nucleation Bursts During Solution Crystallization in Pure and Impure Solvent. Crystal growth \& des., 2012, 12, 3407-3417. 


\section{For table of content use only.}

Title: Batch cooling solution crystallization of ammonium oxalate in the presence of impurities: study of solubility, supersaturation and steady-state inhibition.

By FEVOTTE Gilles, GHERRAS Nesrine \& MOUTTE Jacques

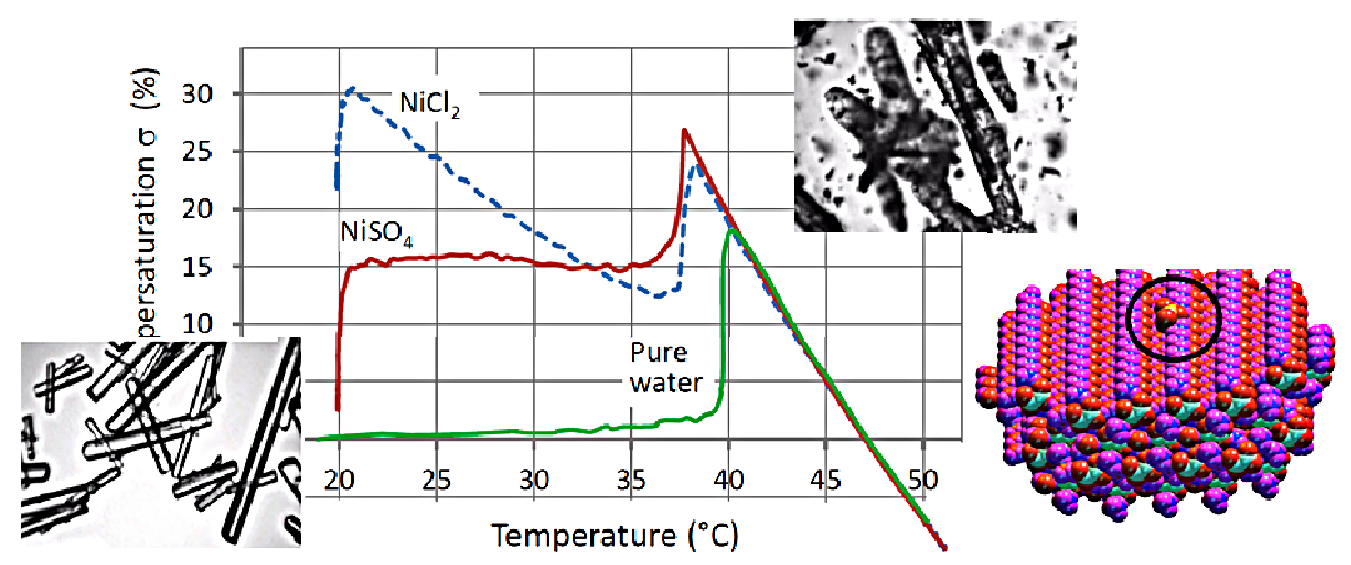

Synopsis.

Papers dealing with the inhibiting effects of impurities in solution crystallization are rather unclear about the appropriate way of defining supersaturation in impure solvents. Setting the correct reference for computing supersaturation in impure solutions is obviously a key-issue for understanding and modeling the dynamics of elementary crystallization phenomena (i.e., nucleation, crystal growth, etc.). This is the object of the present paper. 